\title{
An Intramolecular Diels-Alder Approach to the Eunicellins: Enantioselective Total Synthesis of Ophirin B
}

Michael T. Crimmins* and Brandon H. Brown

Venable and Kenan Laboratories of Chemistry

The University of North Carolina at Chapel Hill

Chapel Hill, North Carolina 27599-3290

crimmins@email.unc.edu 
$400 \mathrm{MHz} \quad \mathrm{CDCl} 3$
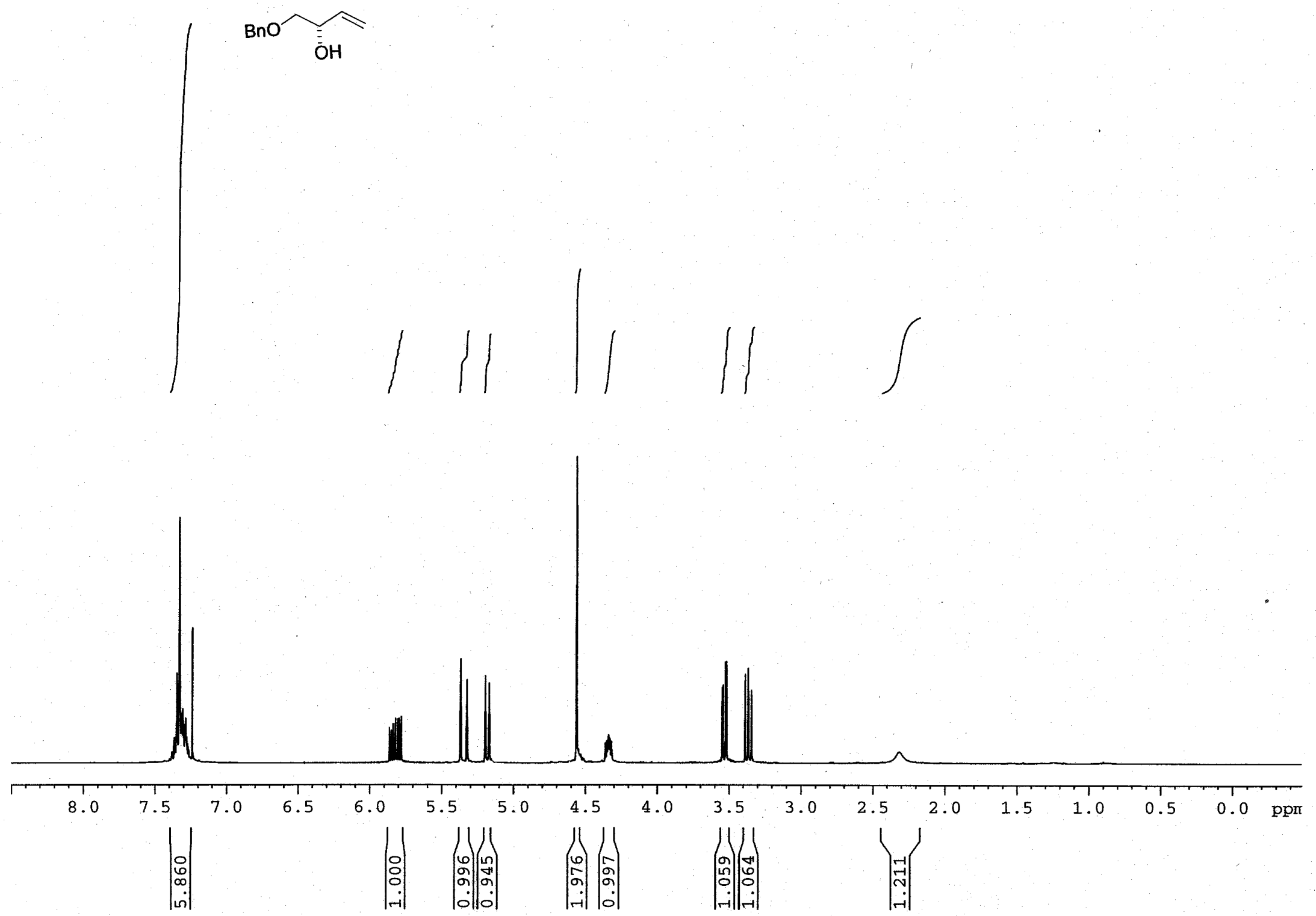
$100 \mathrm{MHz} \mathrm{CDCl} 3$
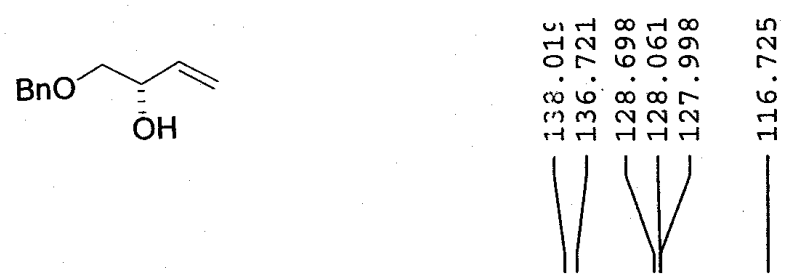

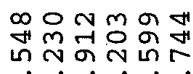

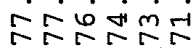

11111

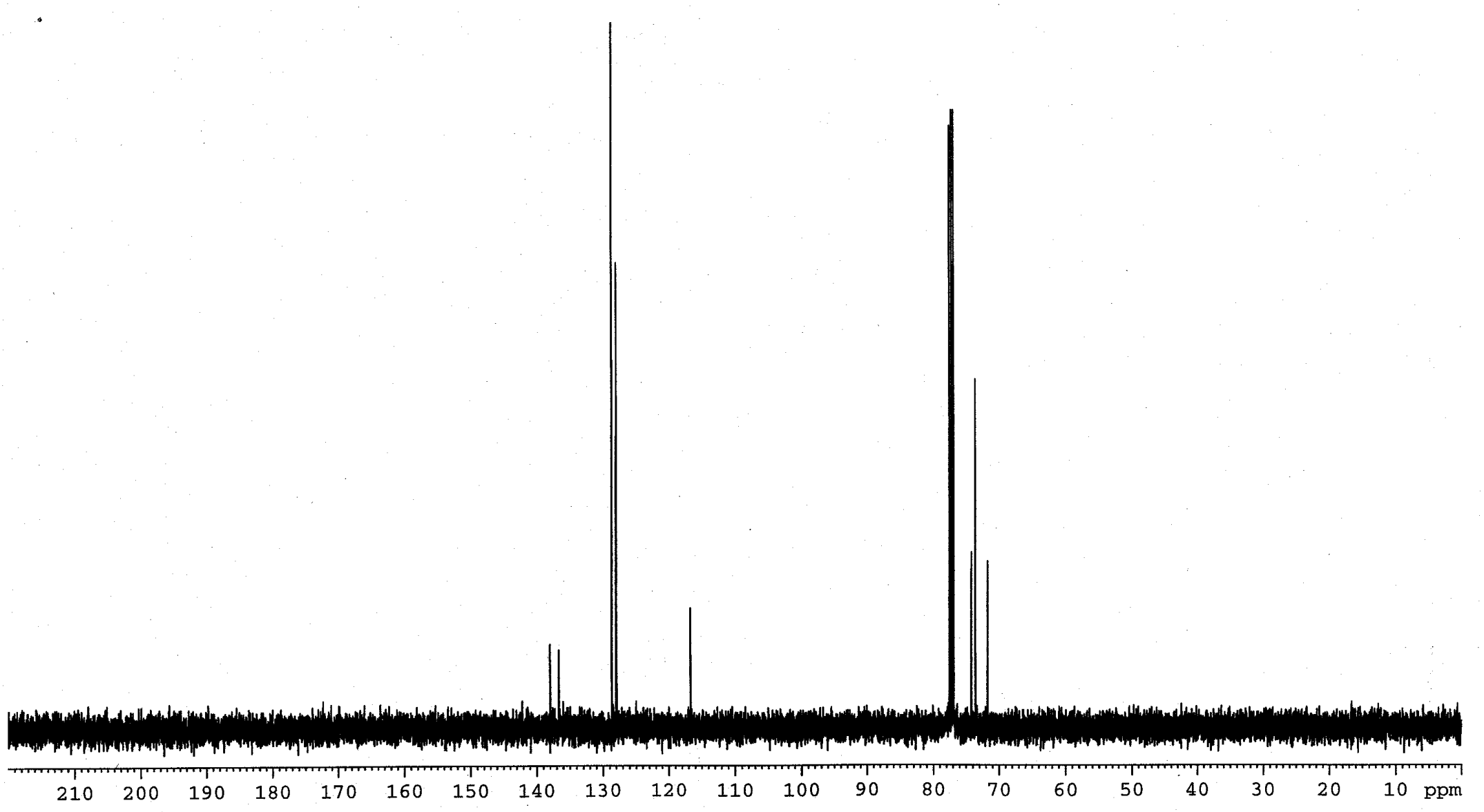




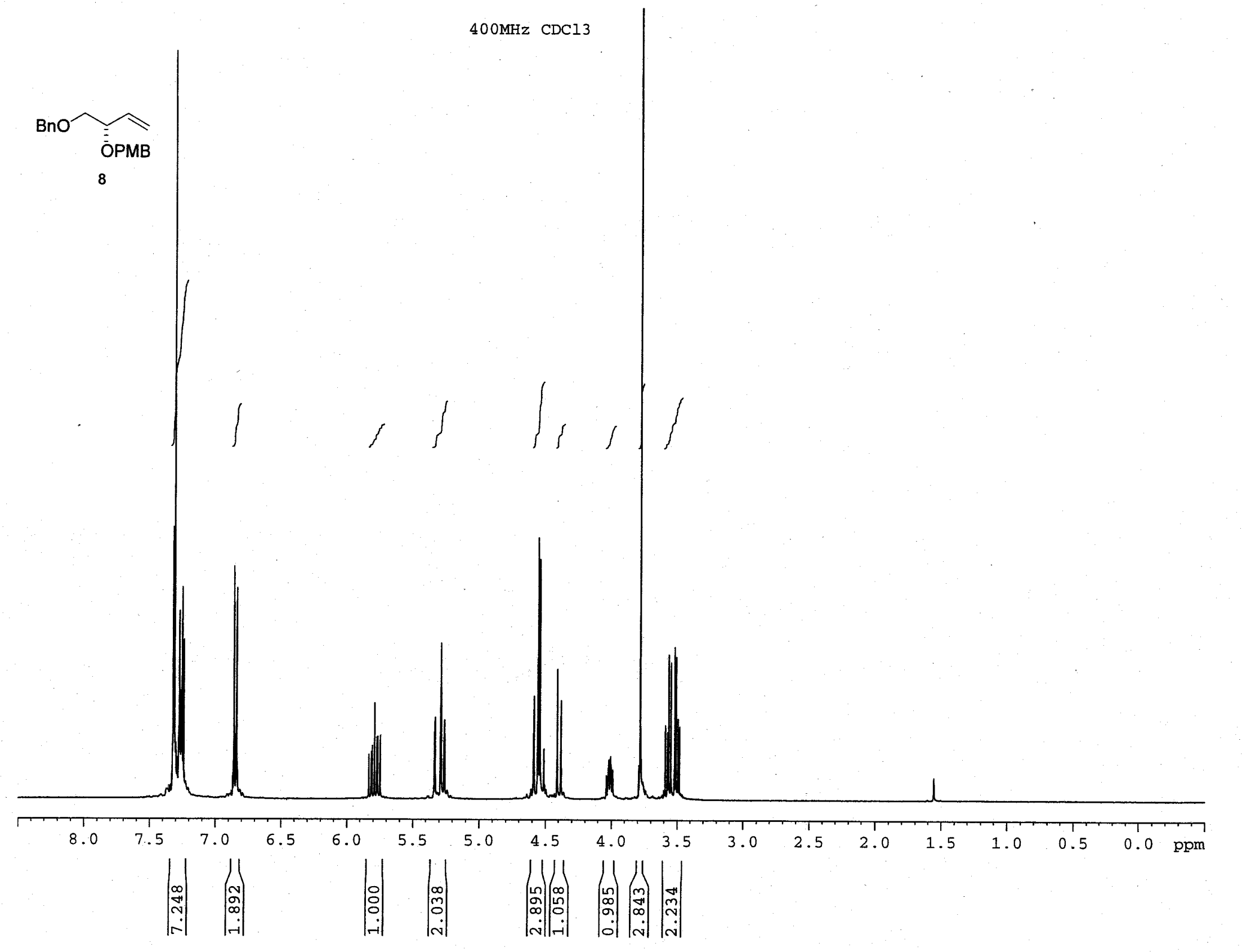


$100 \mathrm{MHz} \quad \mathrm{CDCl} 3$
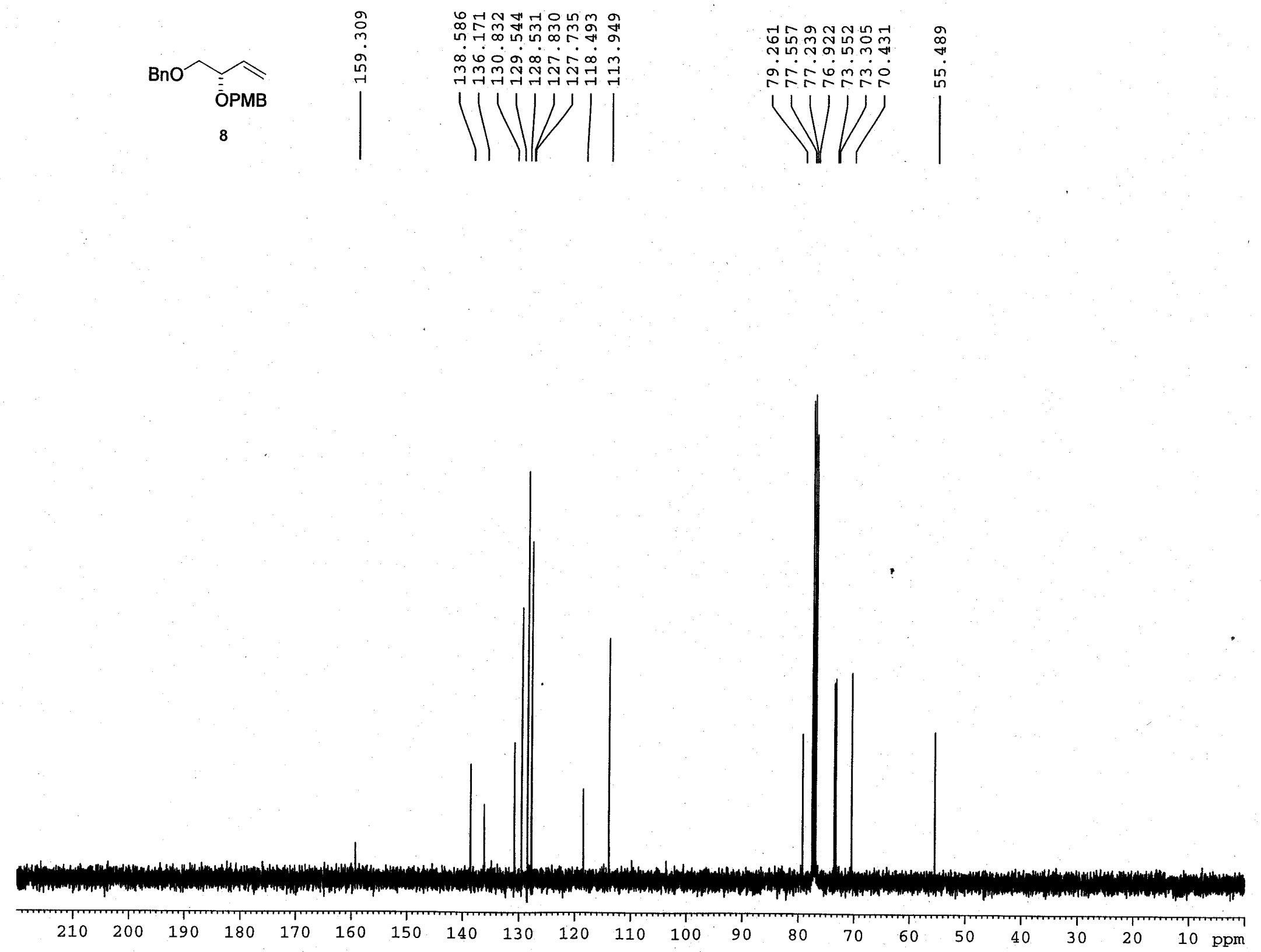
$400 \mathrm{MHz} \mathrm{CDCl} 3$

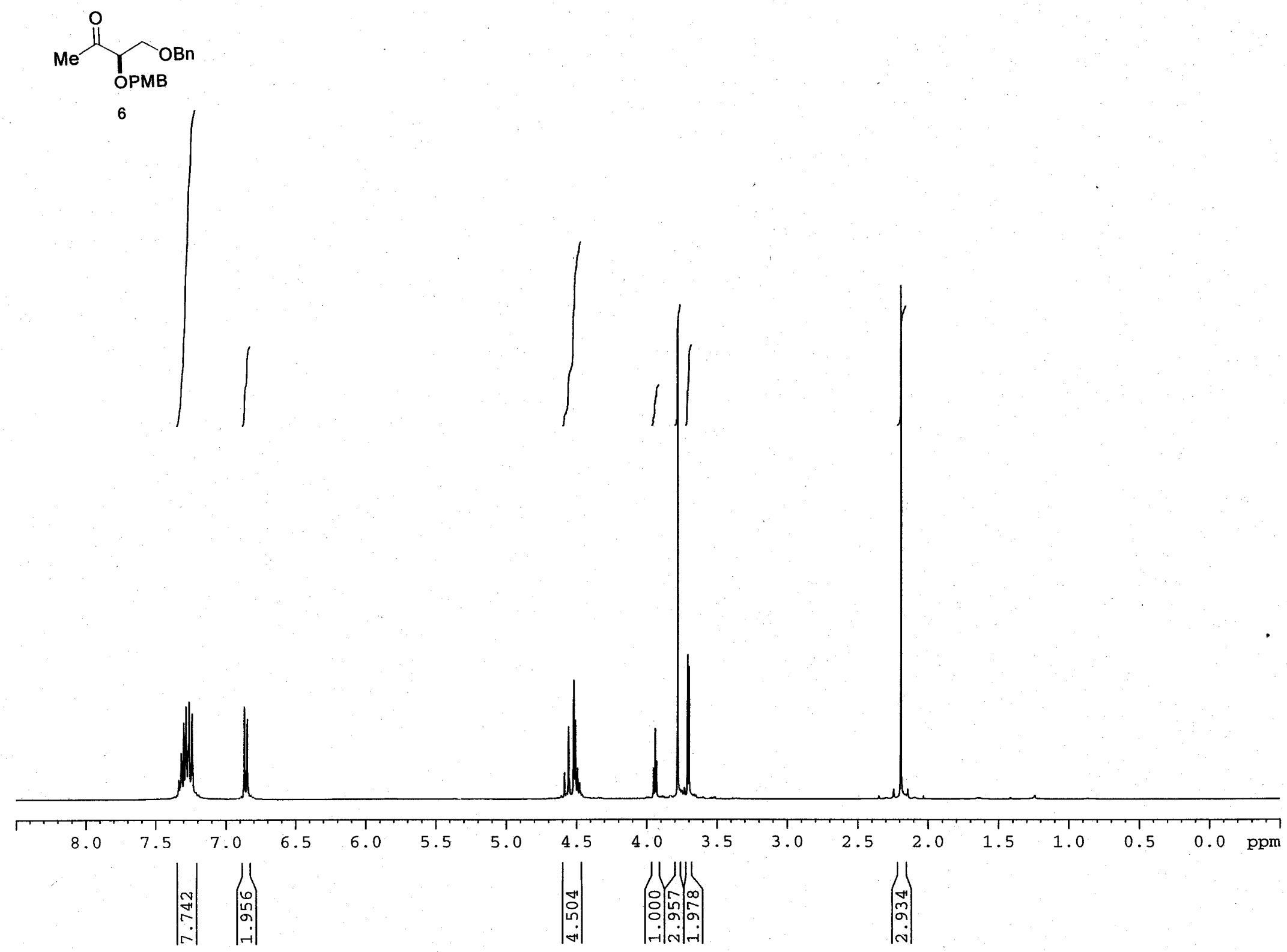


$100 \mathrm{MHz} \operatorname{CDCl} 3$

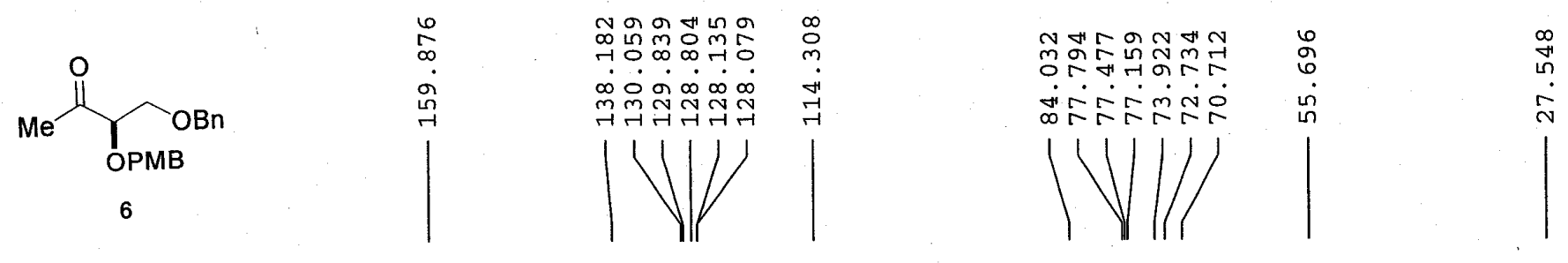

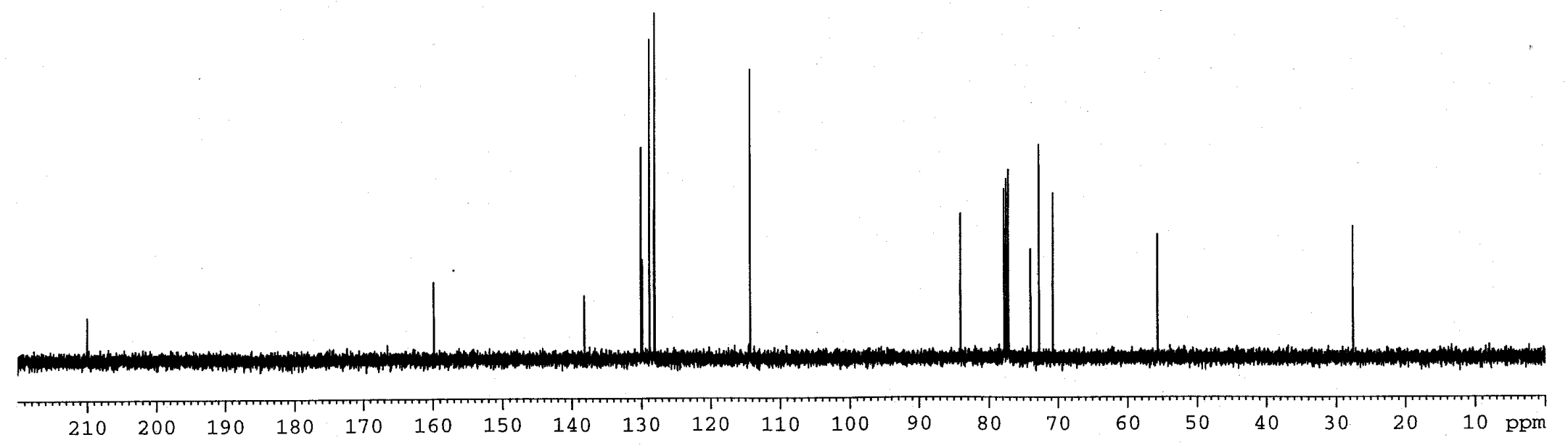




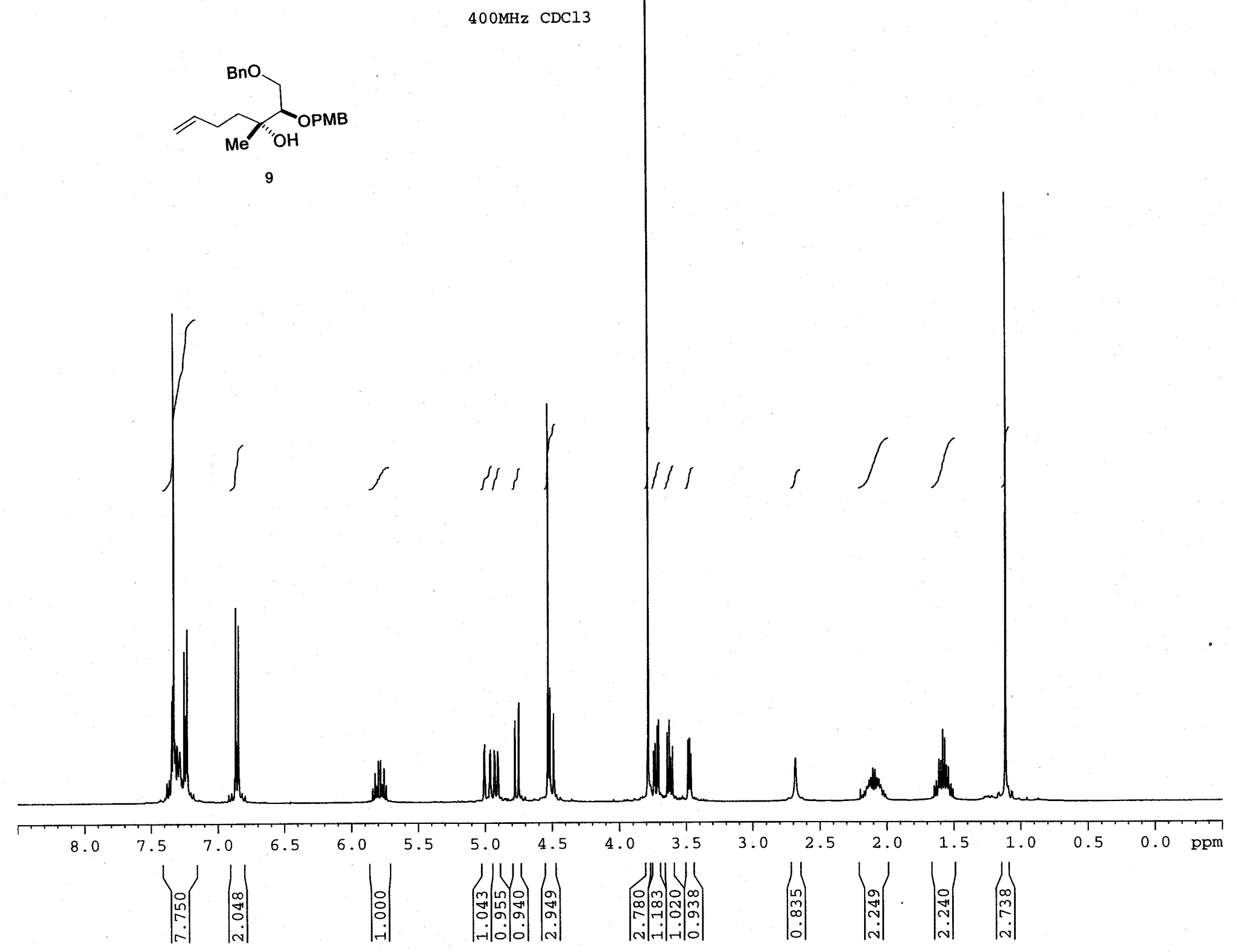


100MHz CDC13
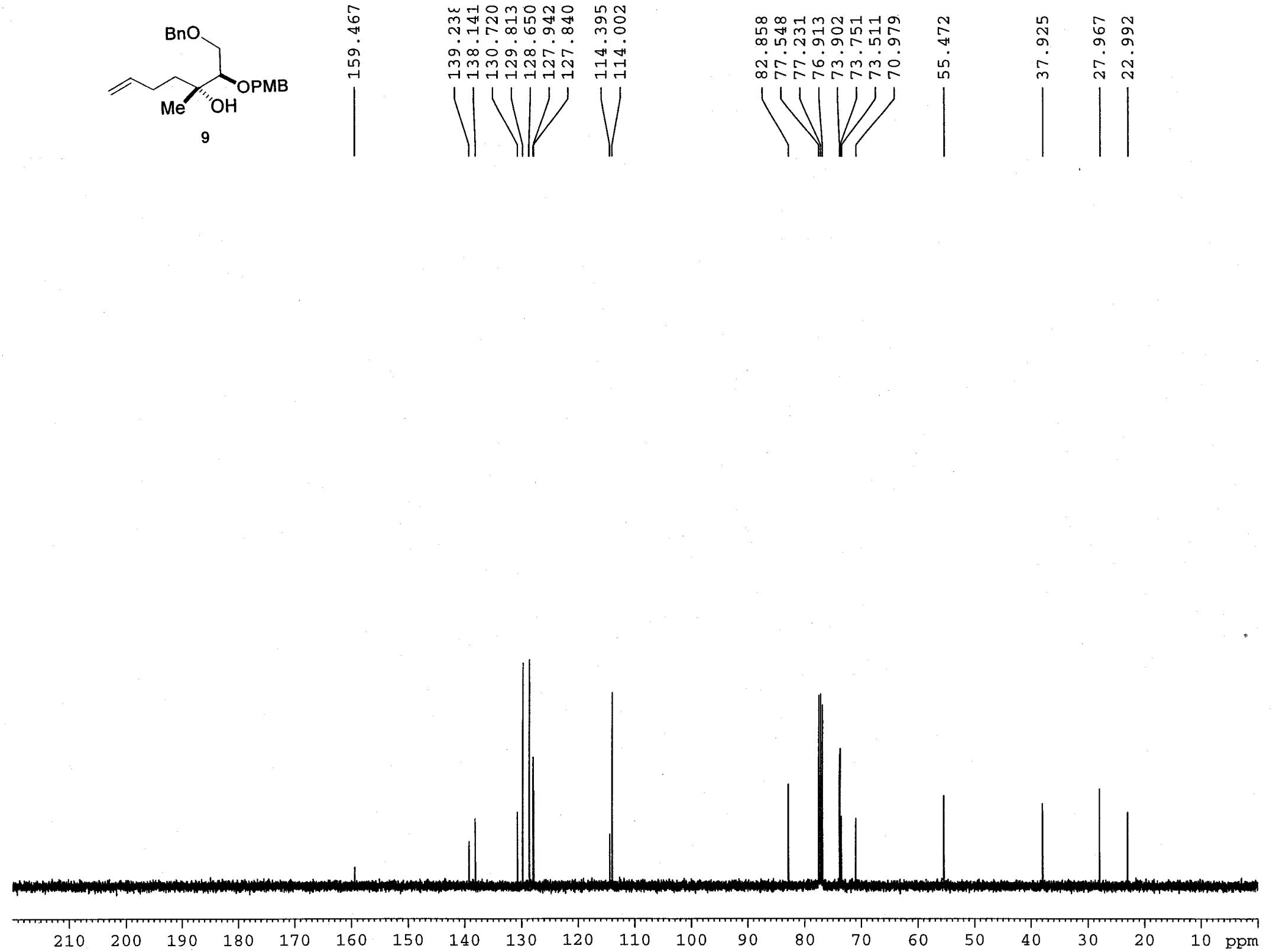


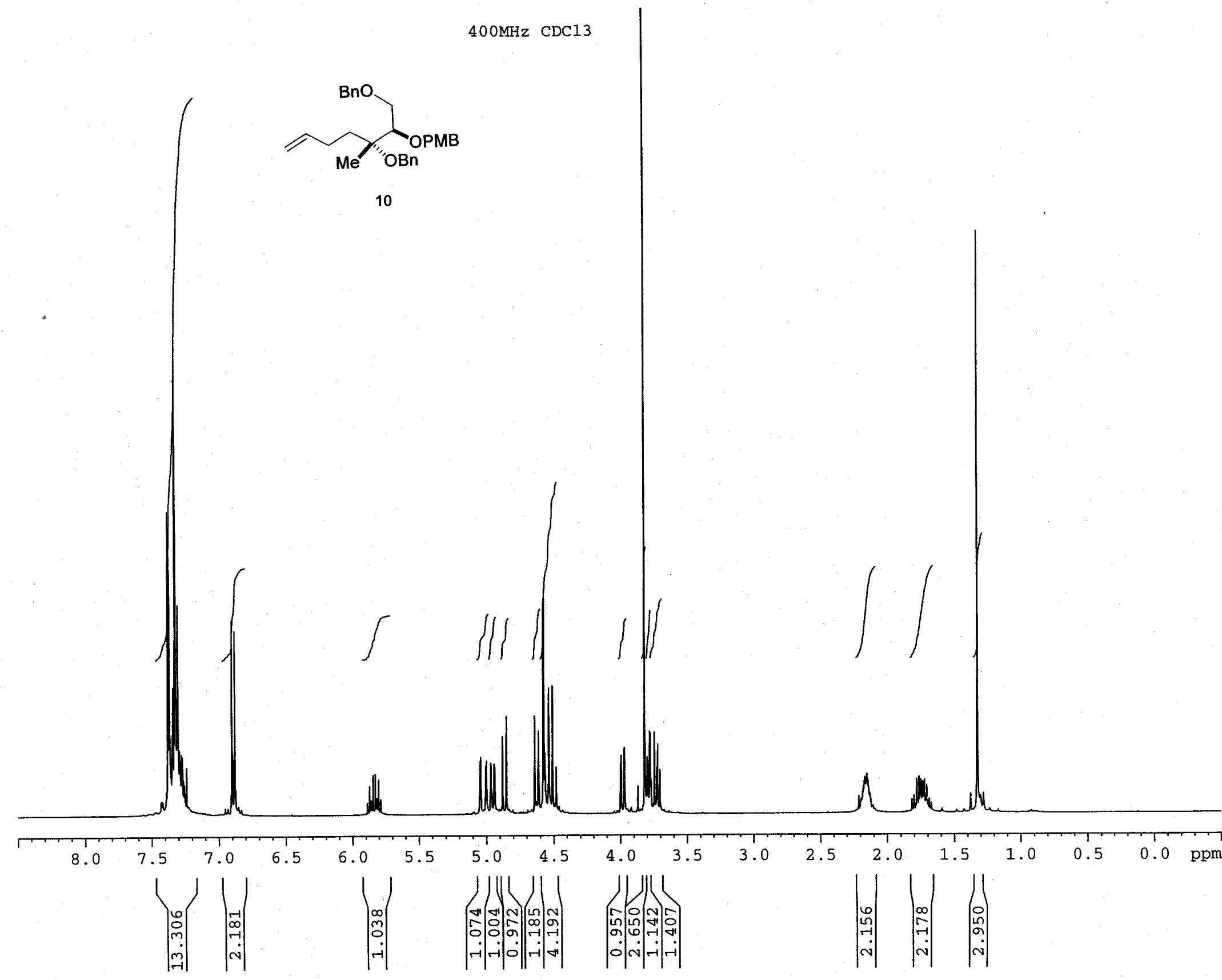


$100 \mathrm{MHz} \mathrm{CDC} 13$
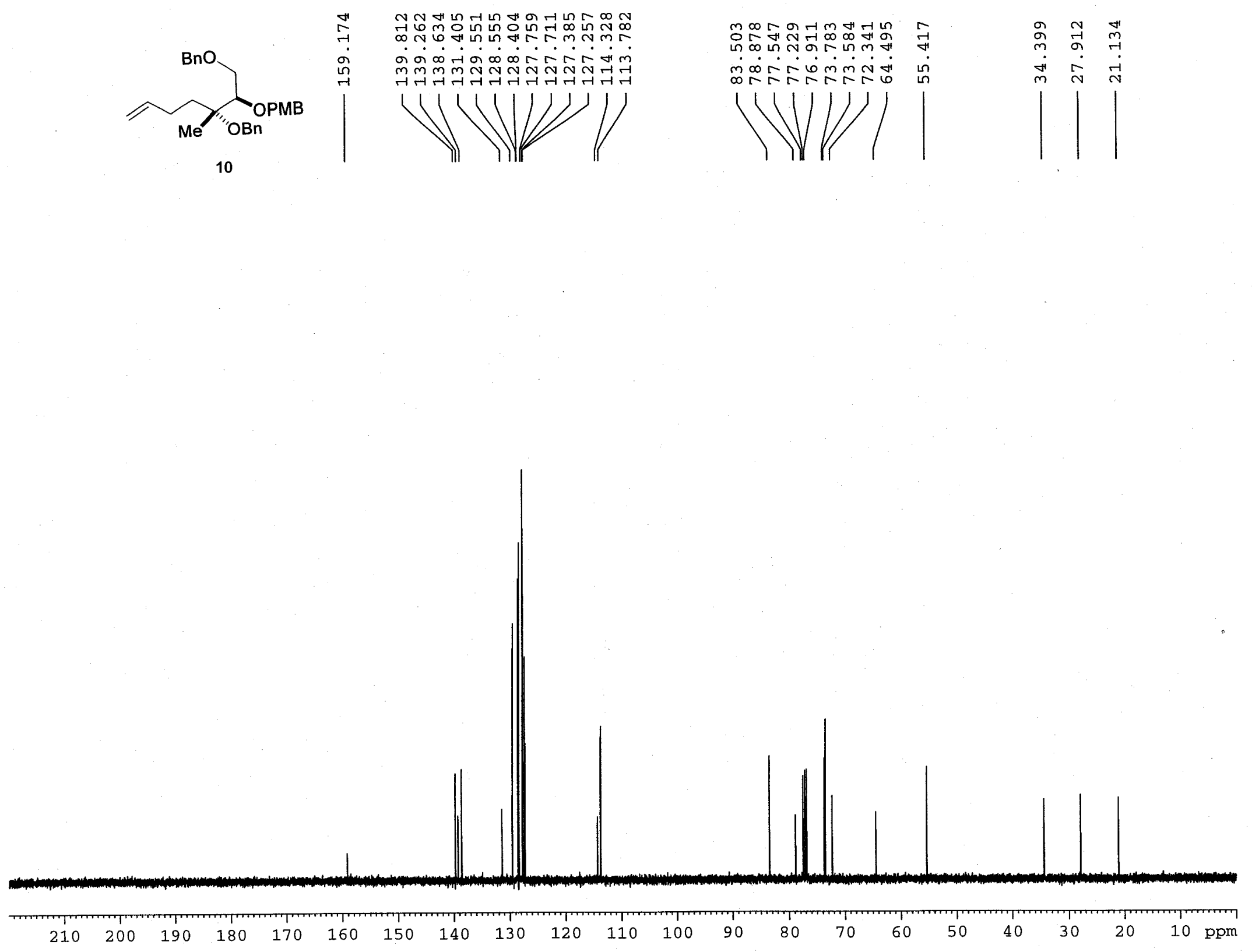


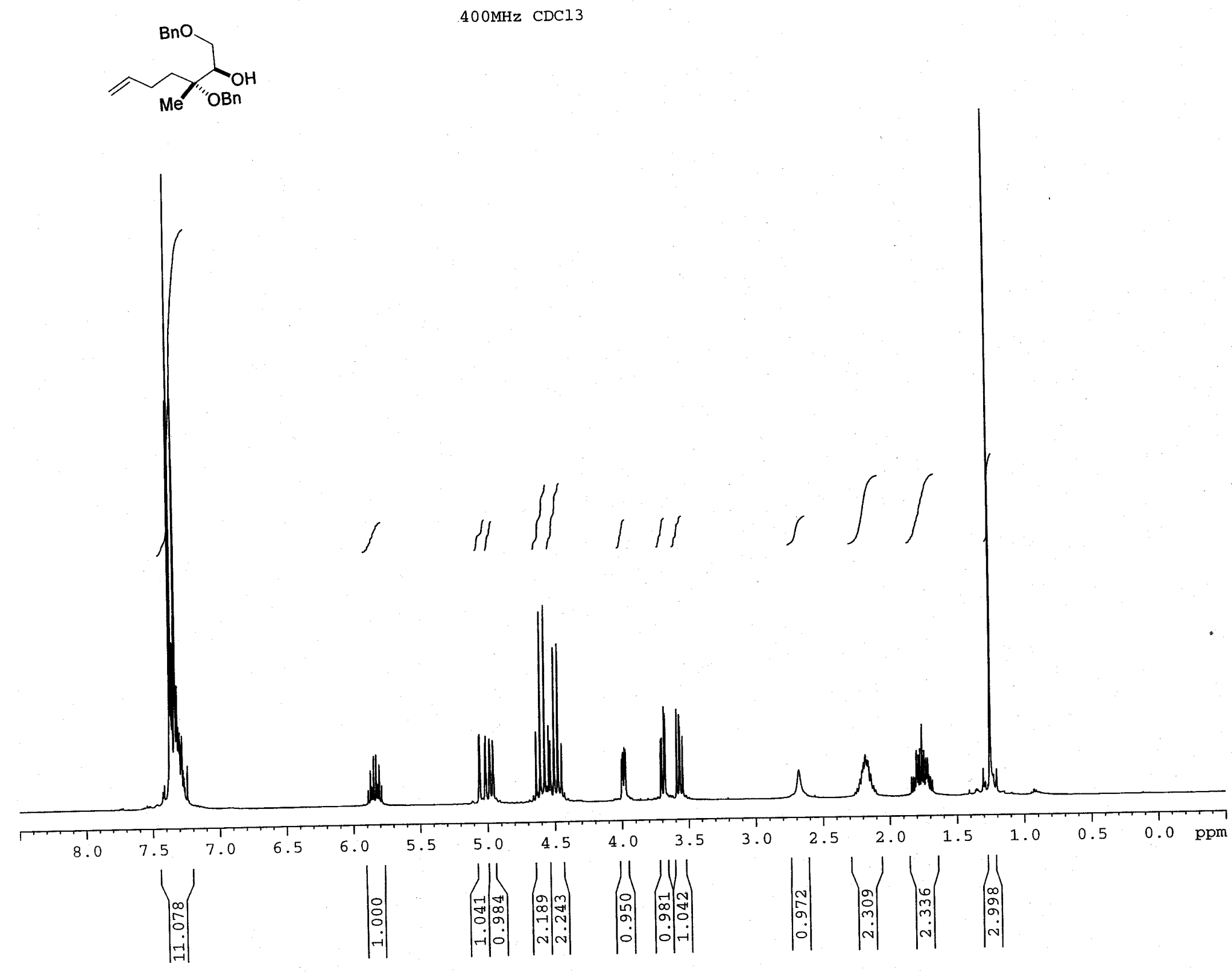


$100 \mathrm{MHz} \operatorname{CDCl} 3$
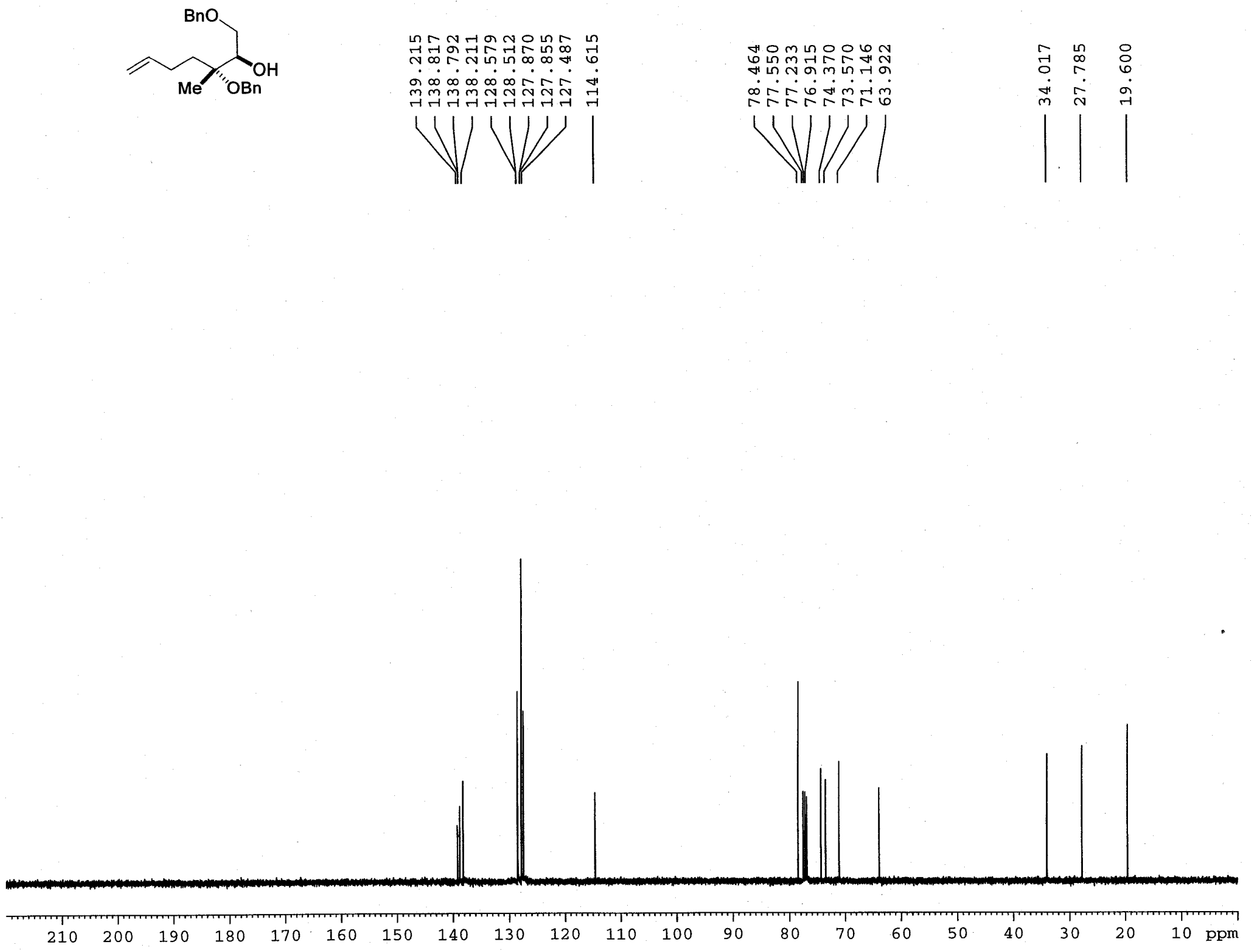
400MHz CDCl3
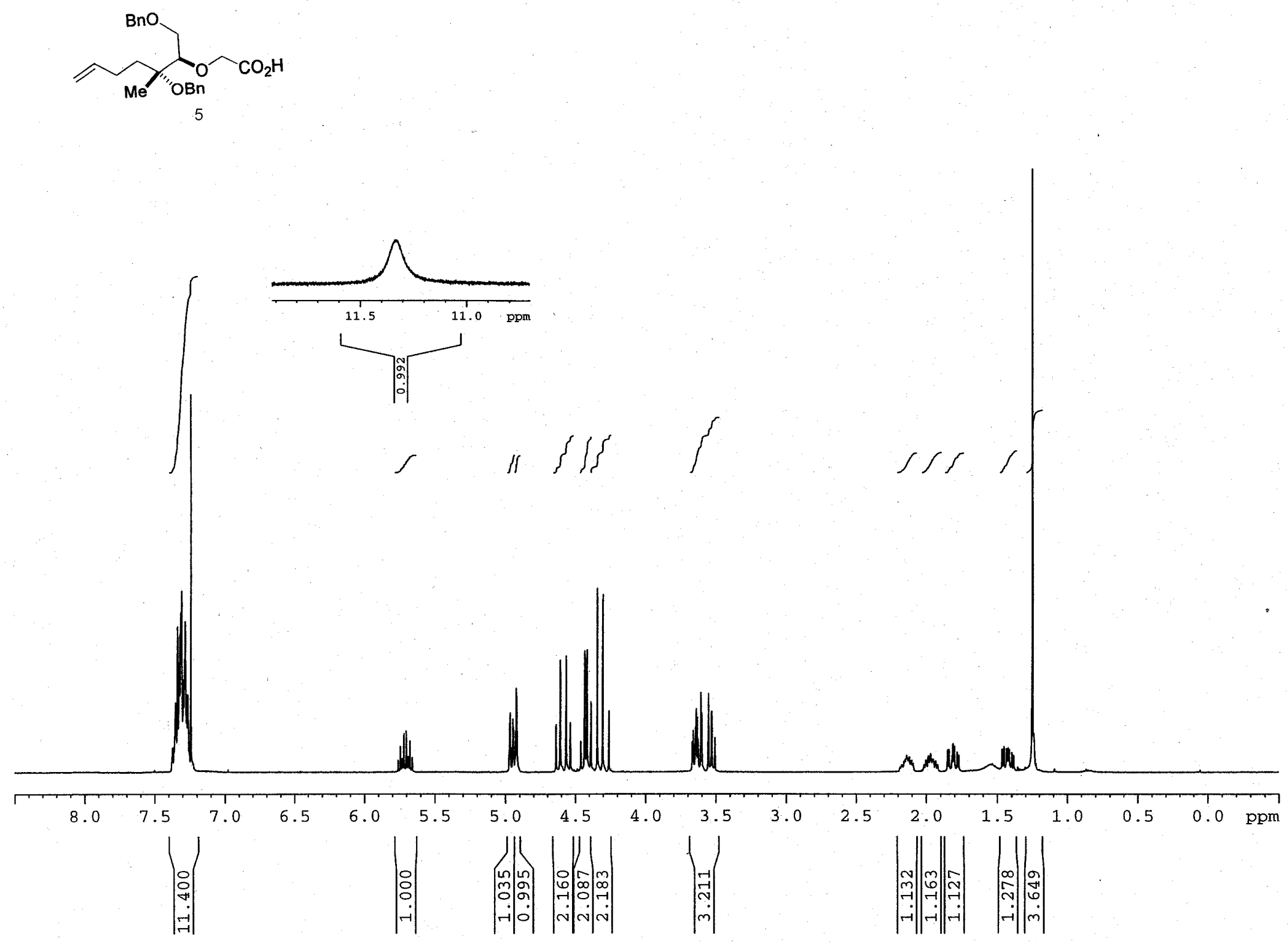
100MHz $\operatorname{CDCl} 3$

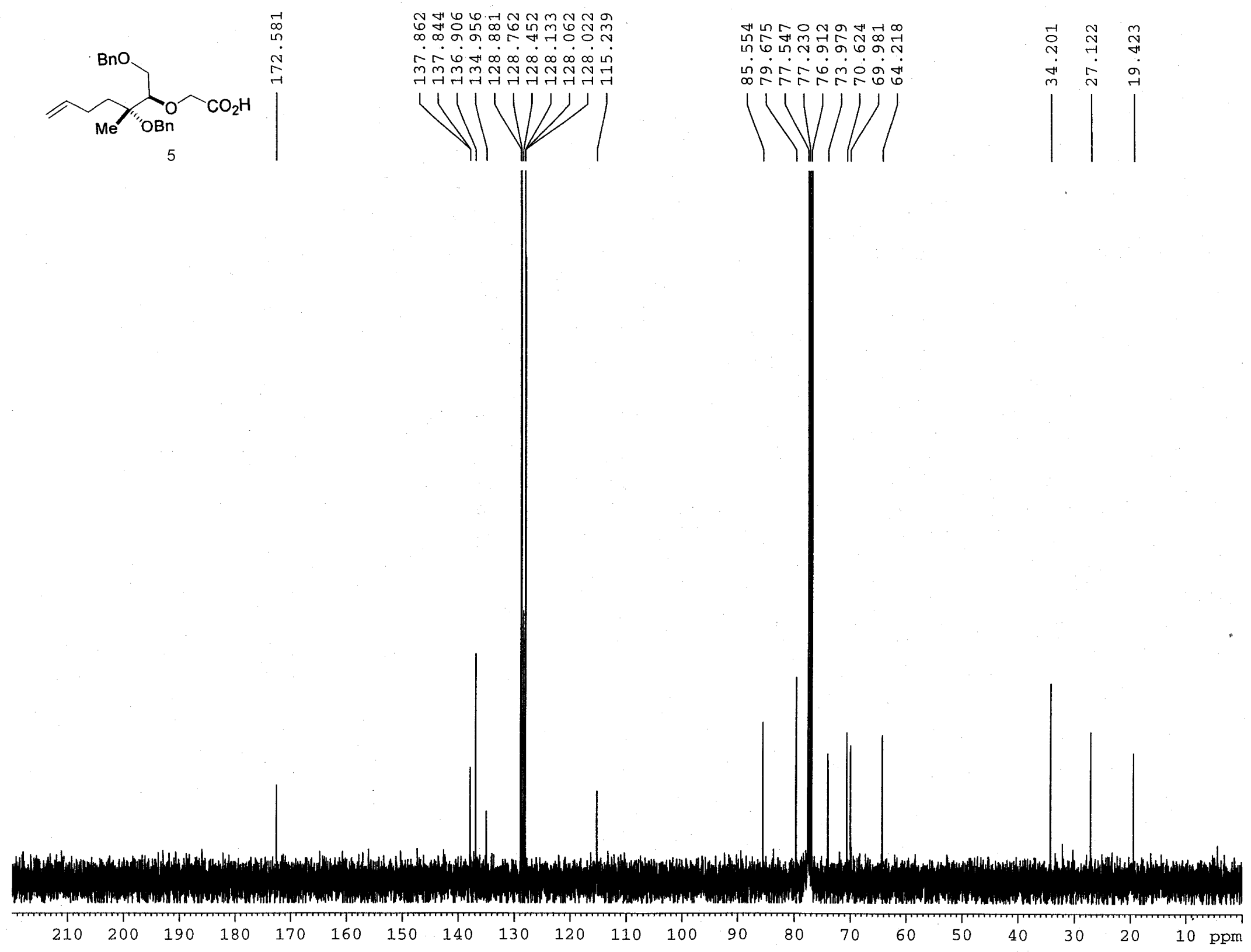


$400 \mathrm{MHz} \mathrm{CDCl} 3$
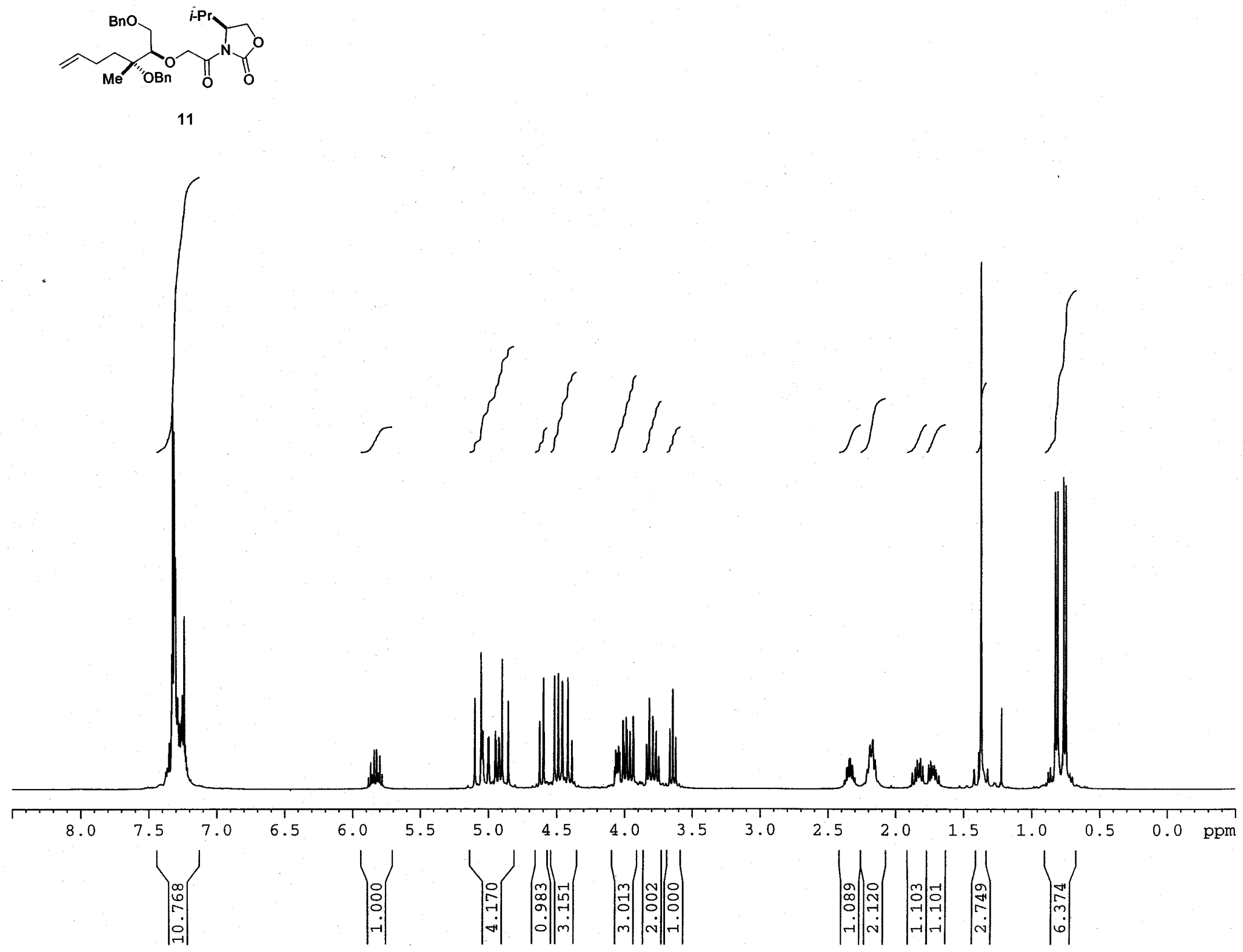
$100 \mathrm{MHz} \mathrm{CDCl} 3$

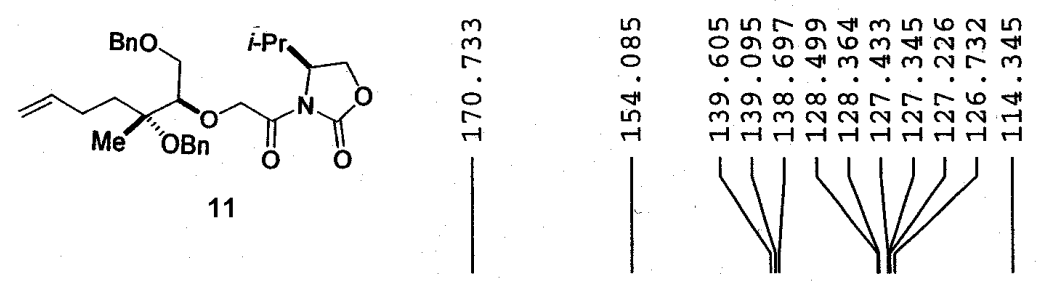

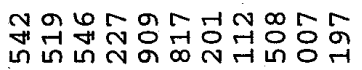

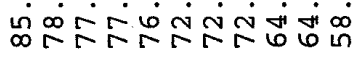

$111 / 1 / 111111$

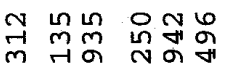

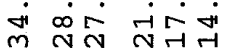
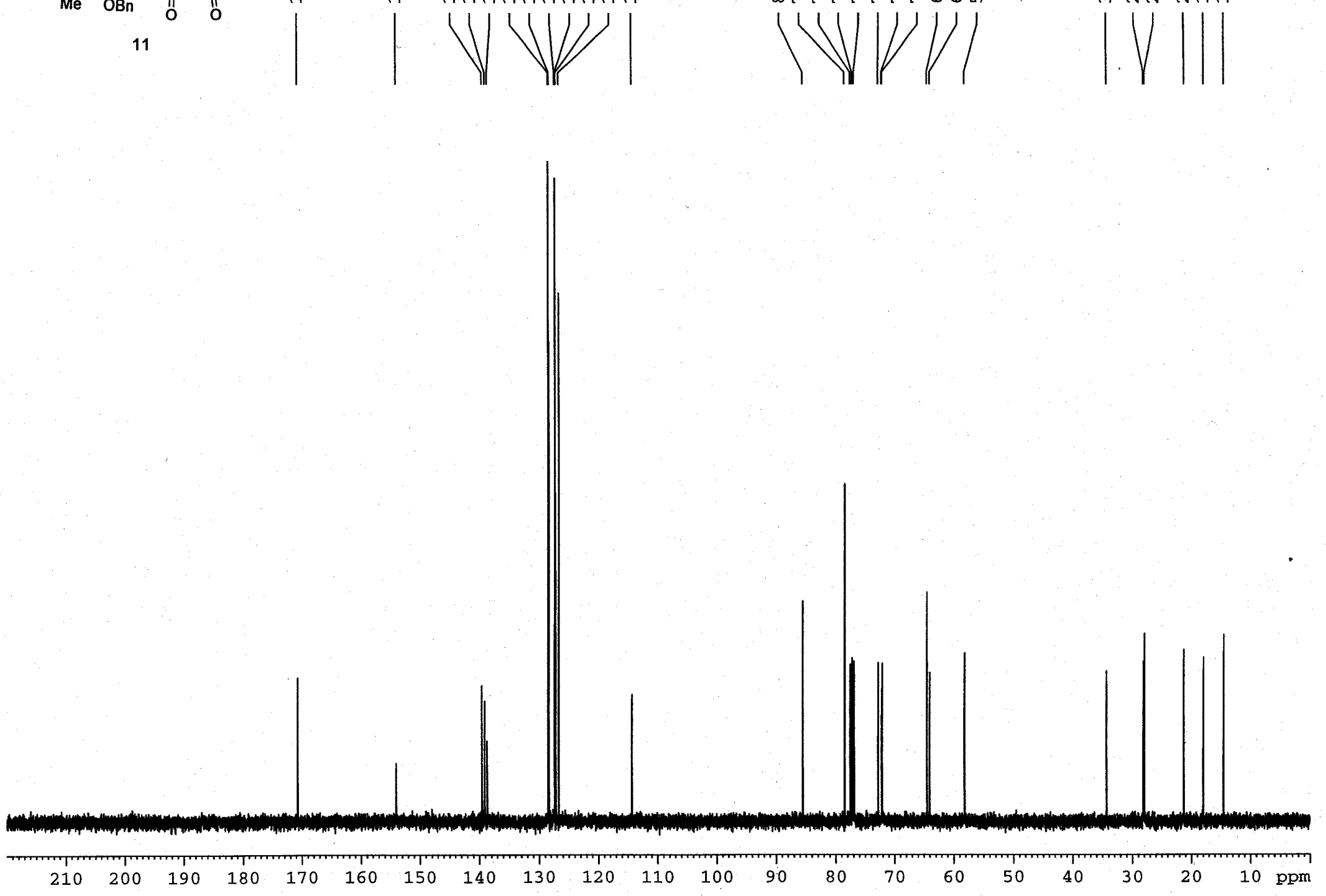


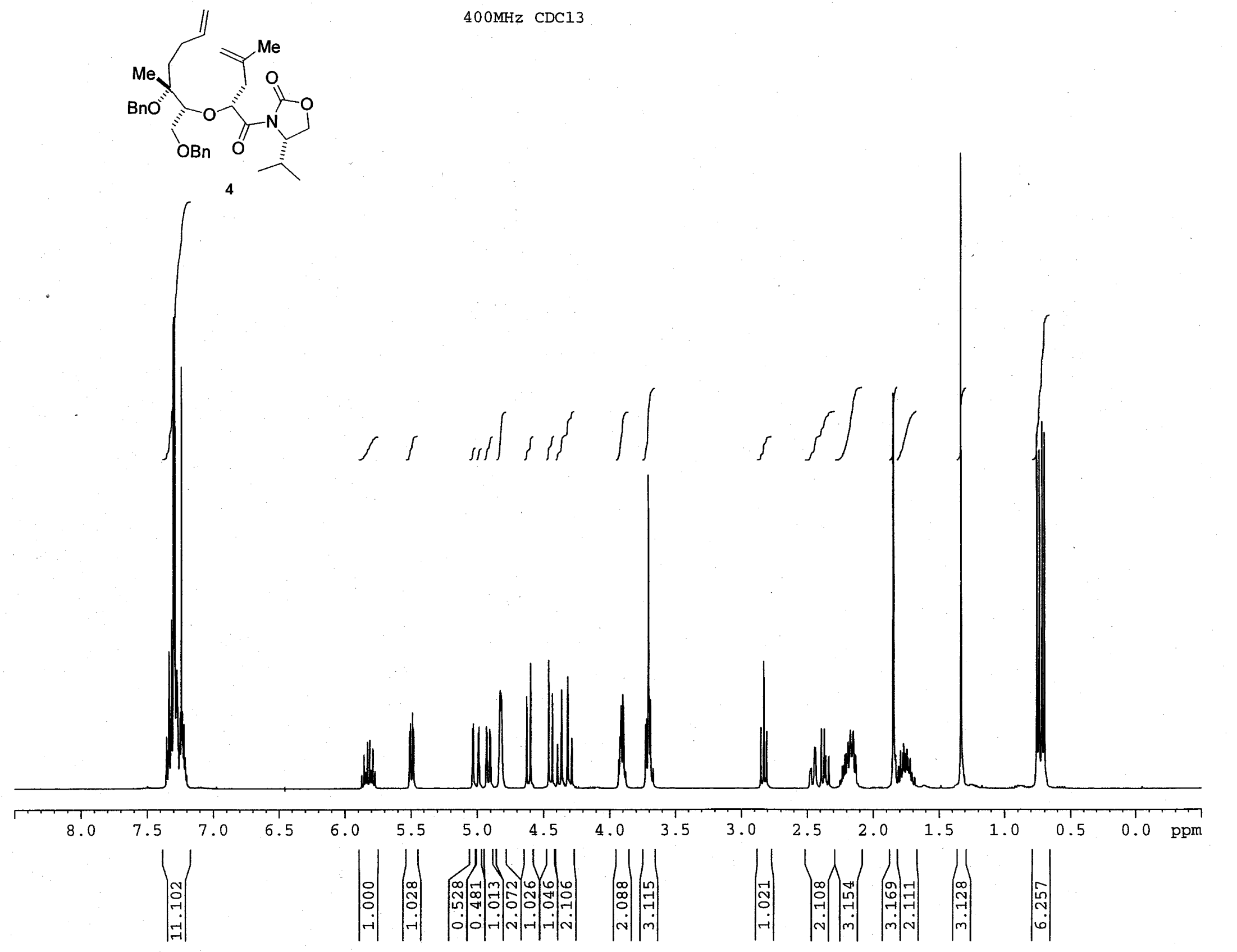



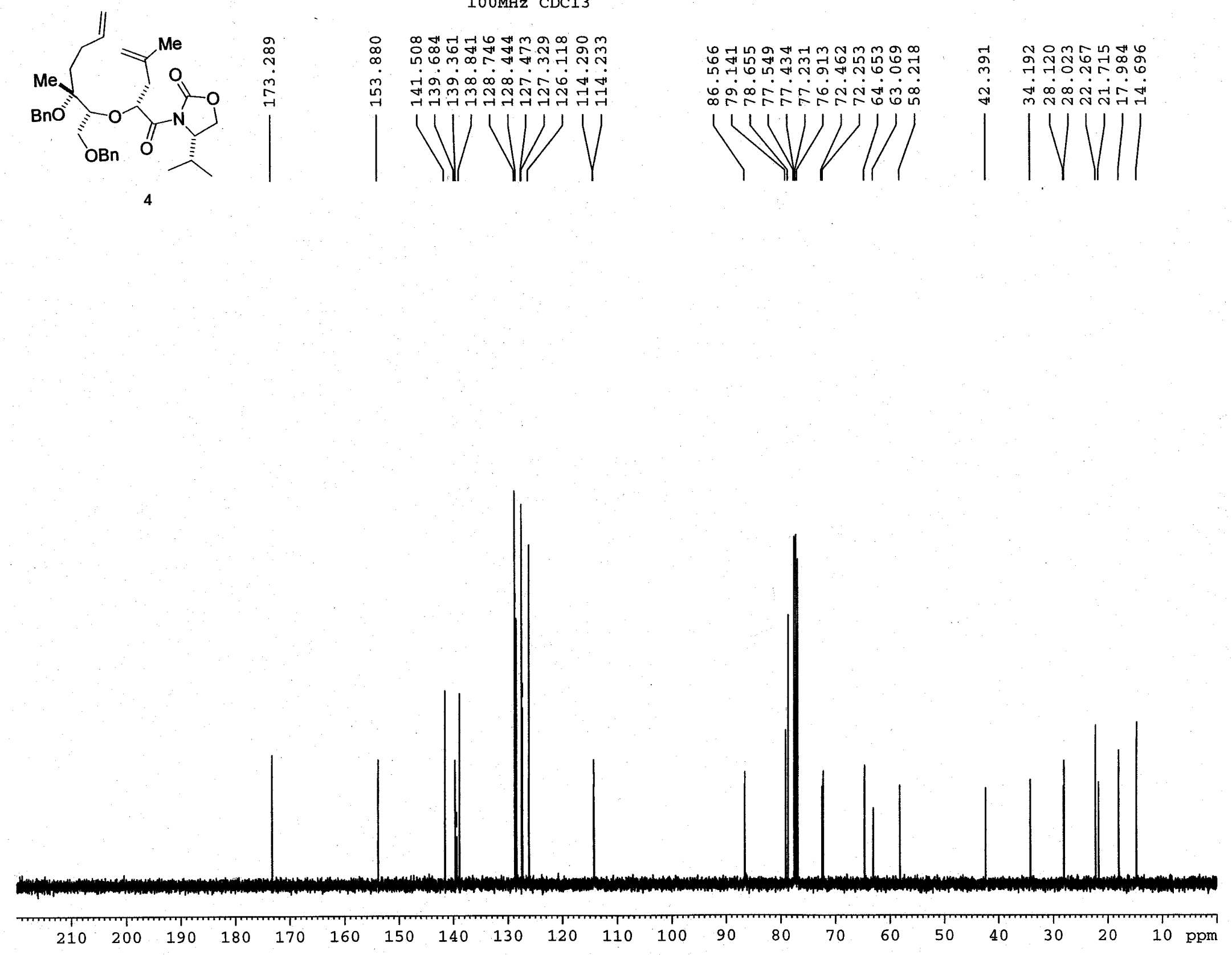


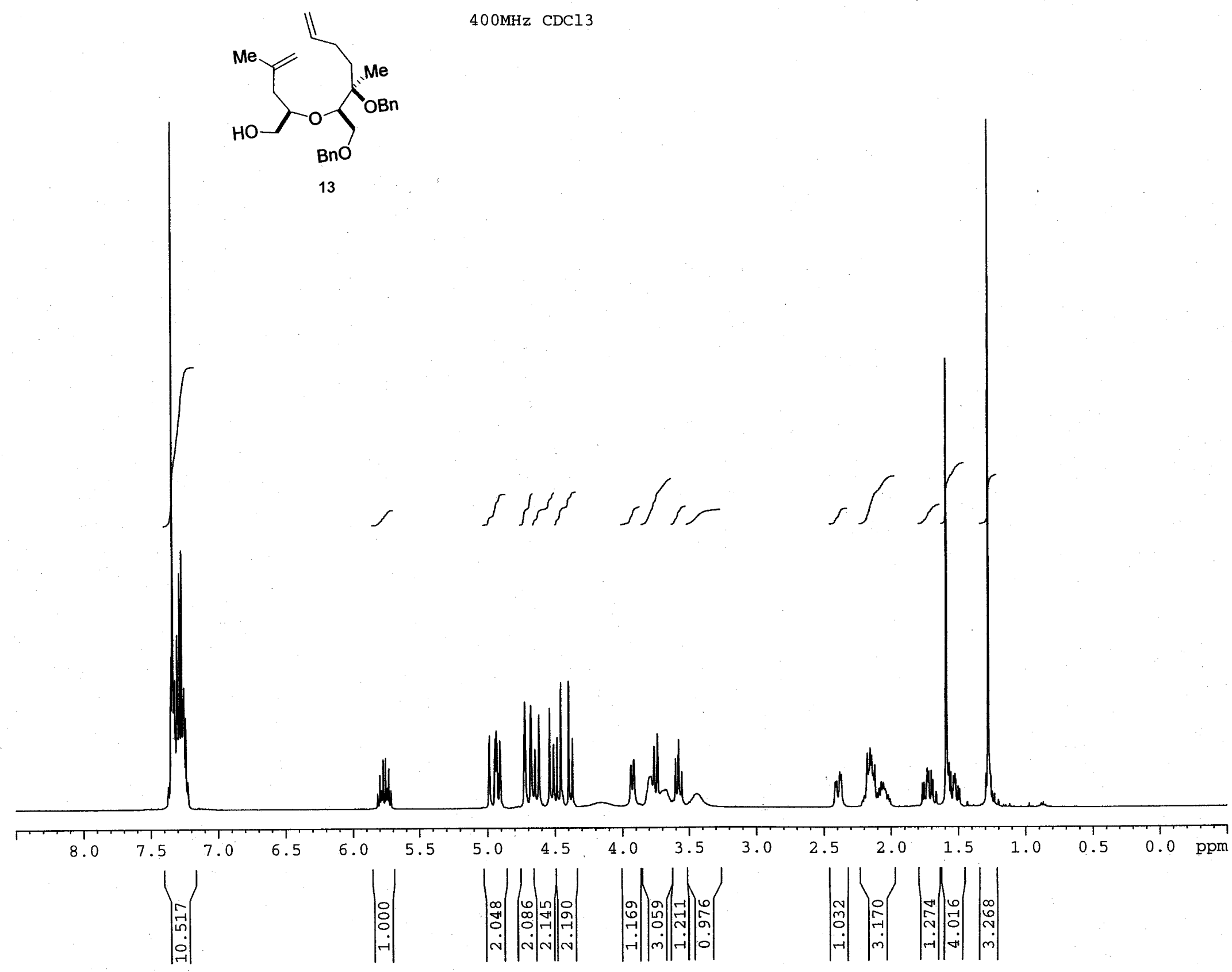




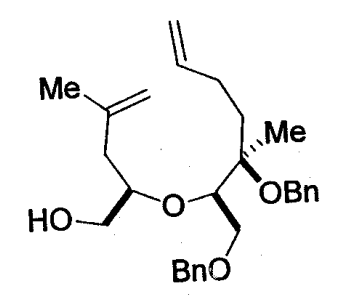

13

$100 \mathrm{MHz} \mathrm{CDCl} 3$

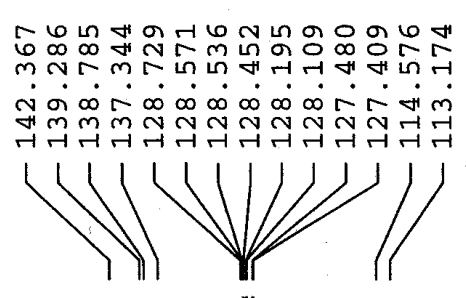

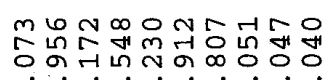

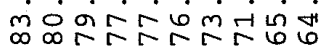

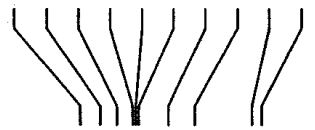
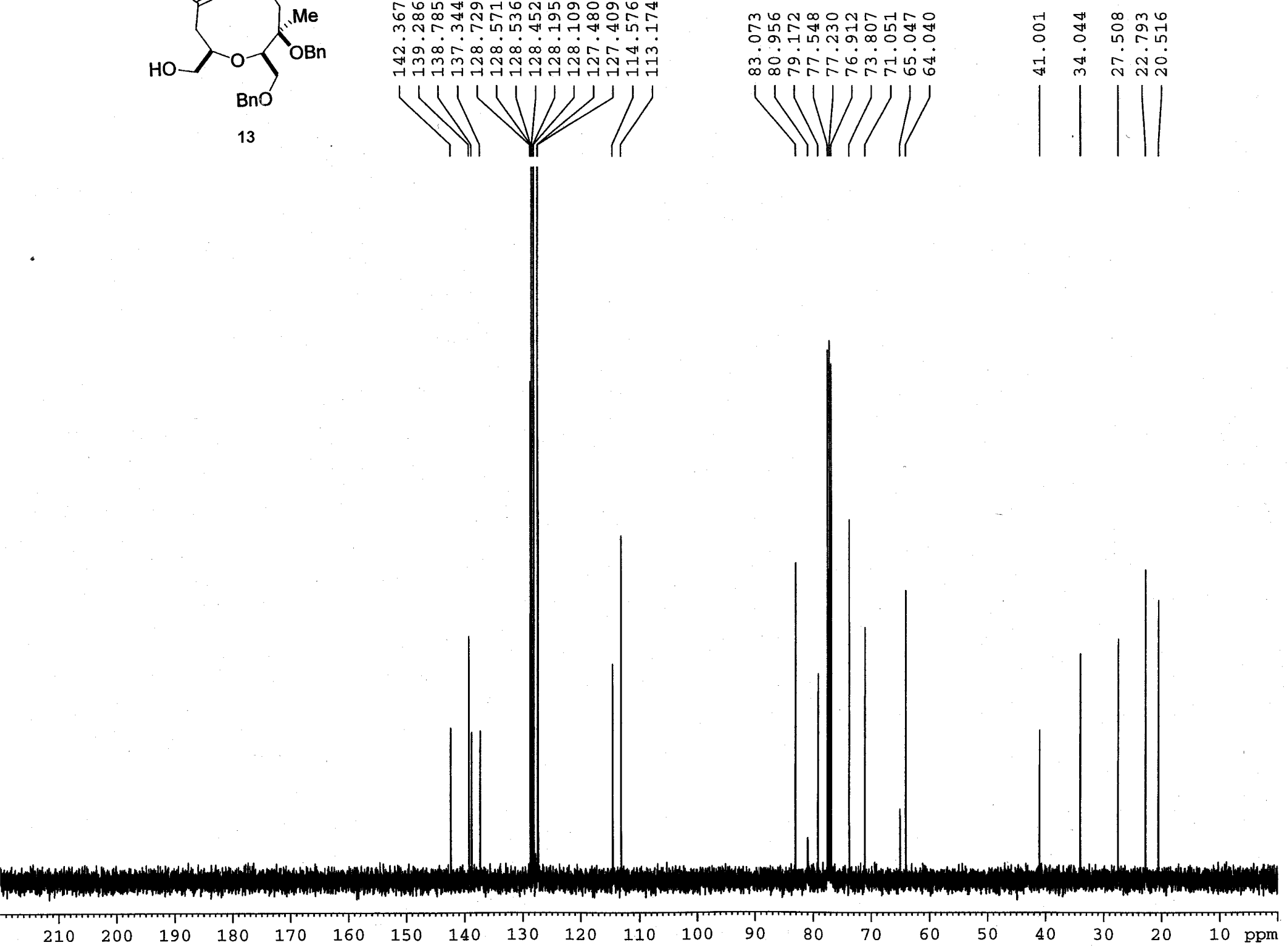
400MHz $\mathrm{CDCl} 3$

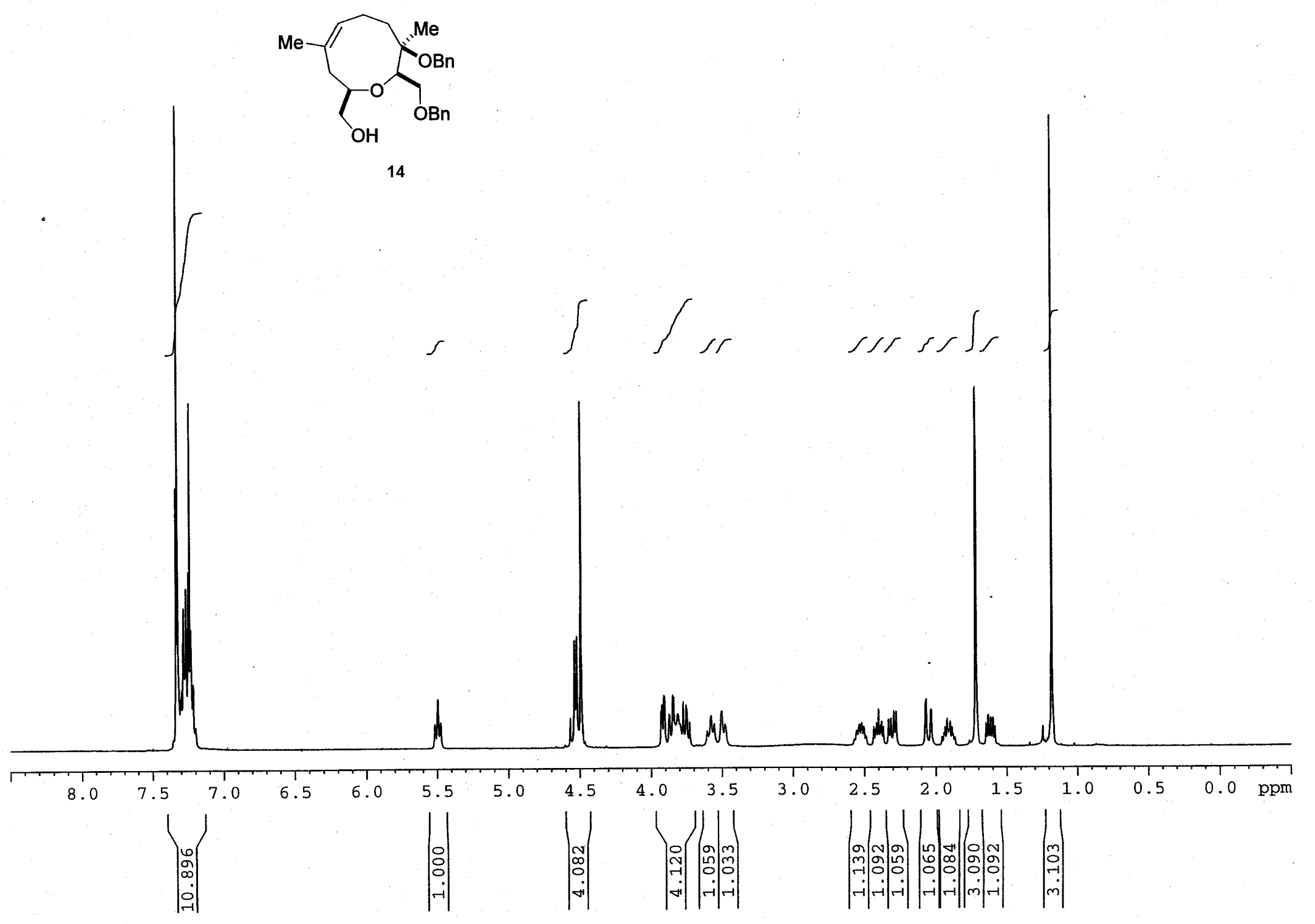


$100 \mathrm{MHz} \mathrm{CDCl}$

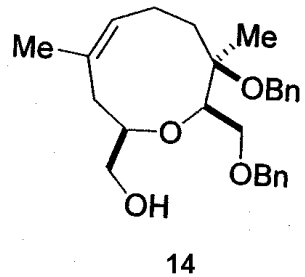

14
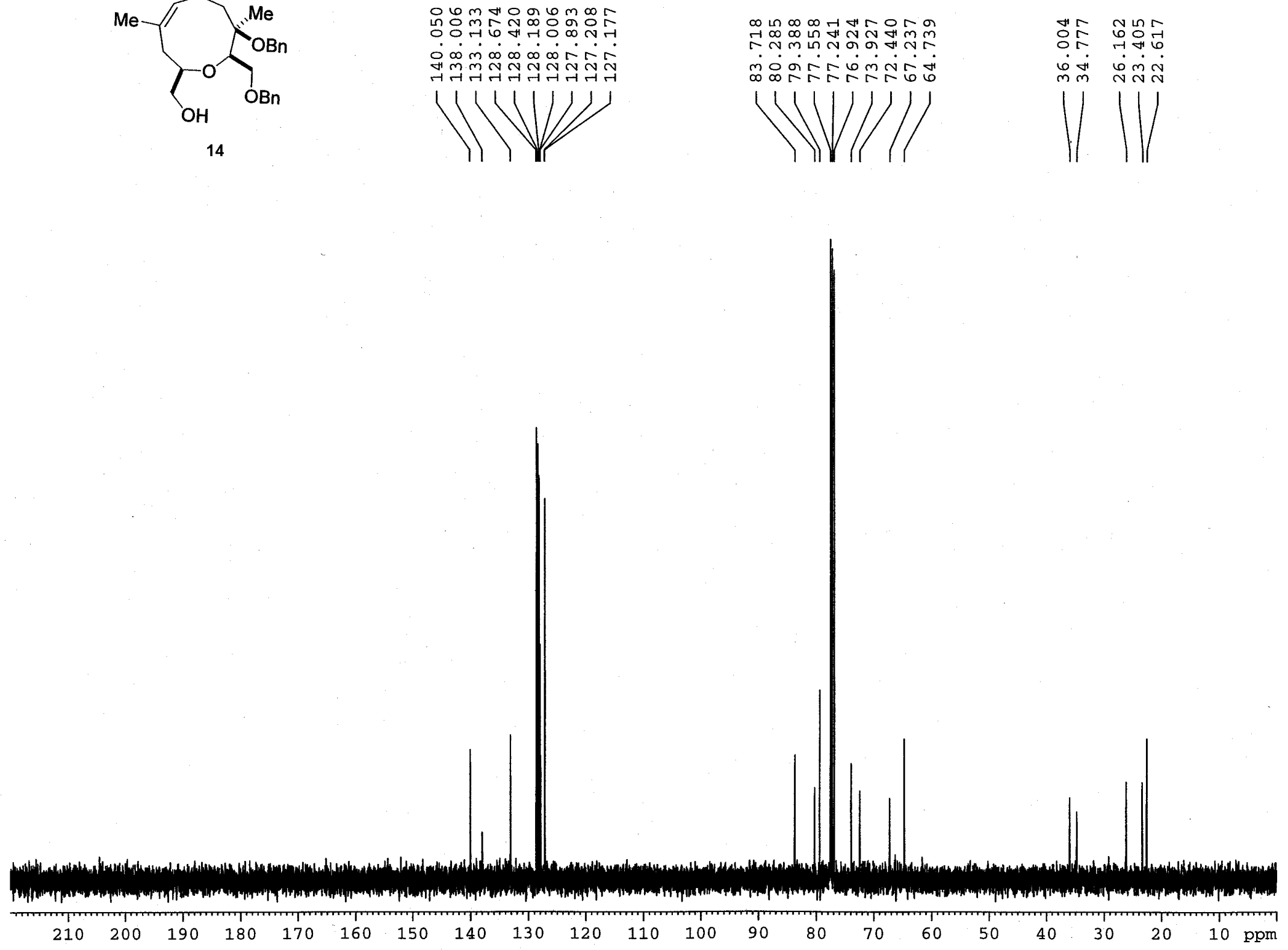
400MHz $\mathrm{CDCl} 3$

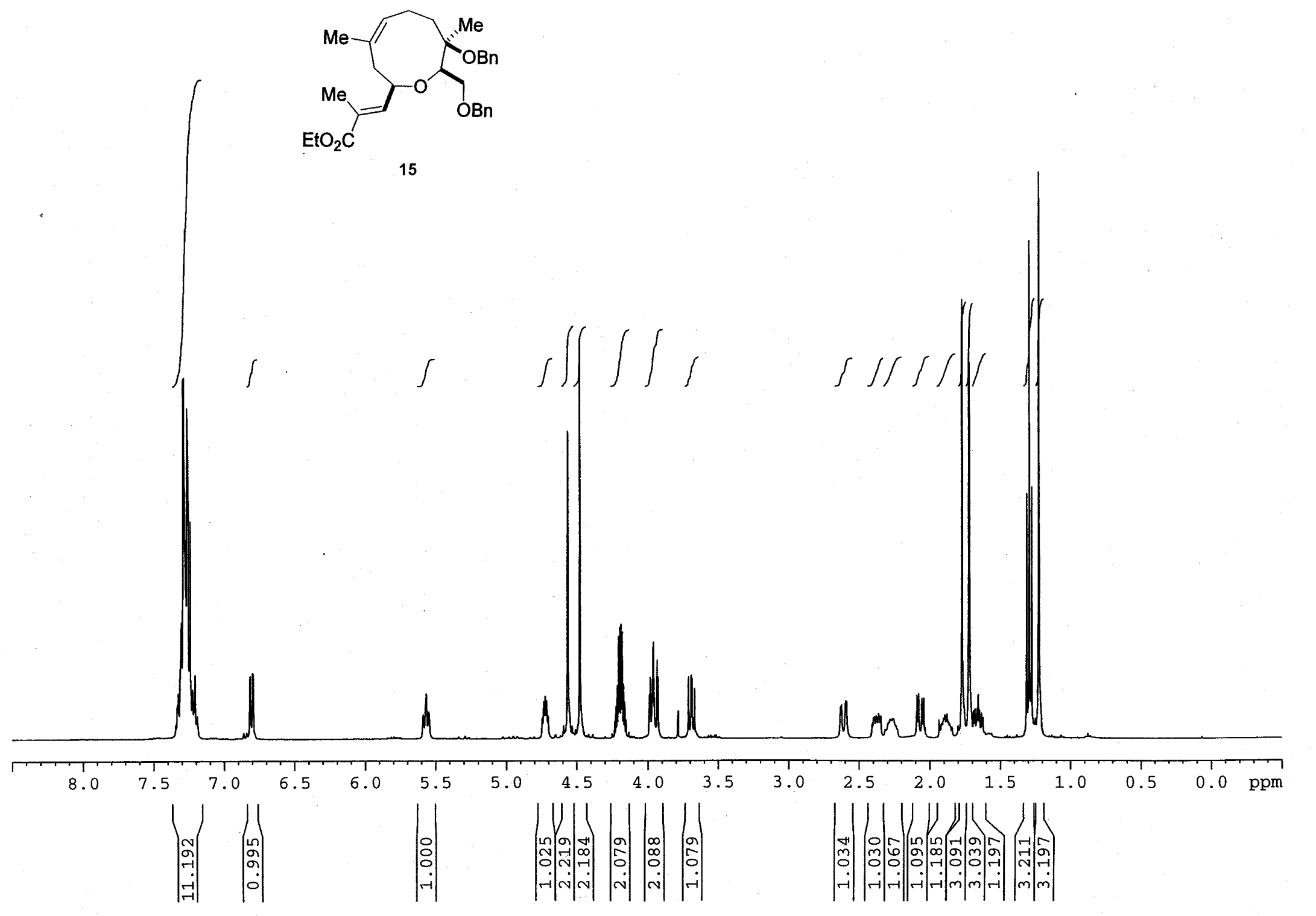


100MHz $\mathrm{CDCl} 3$
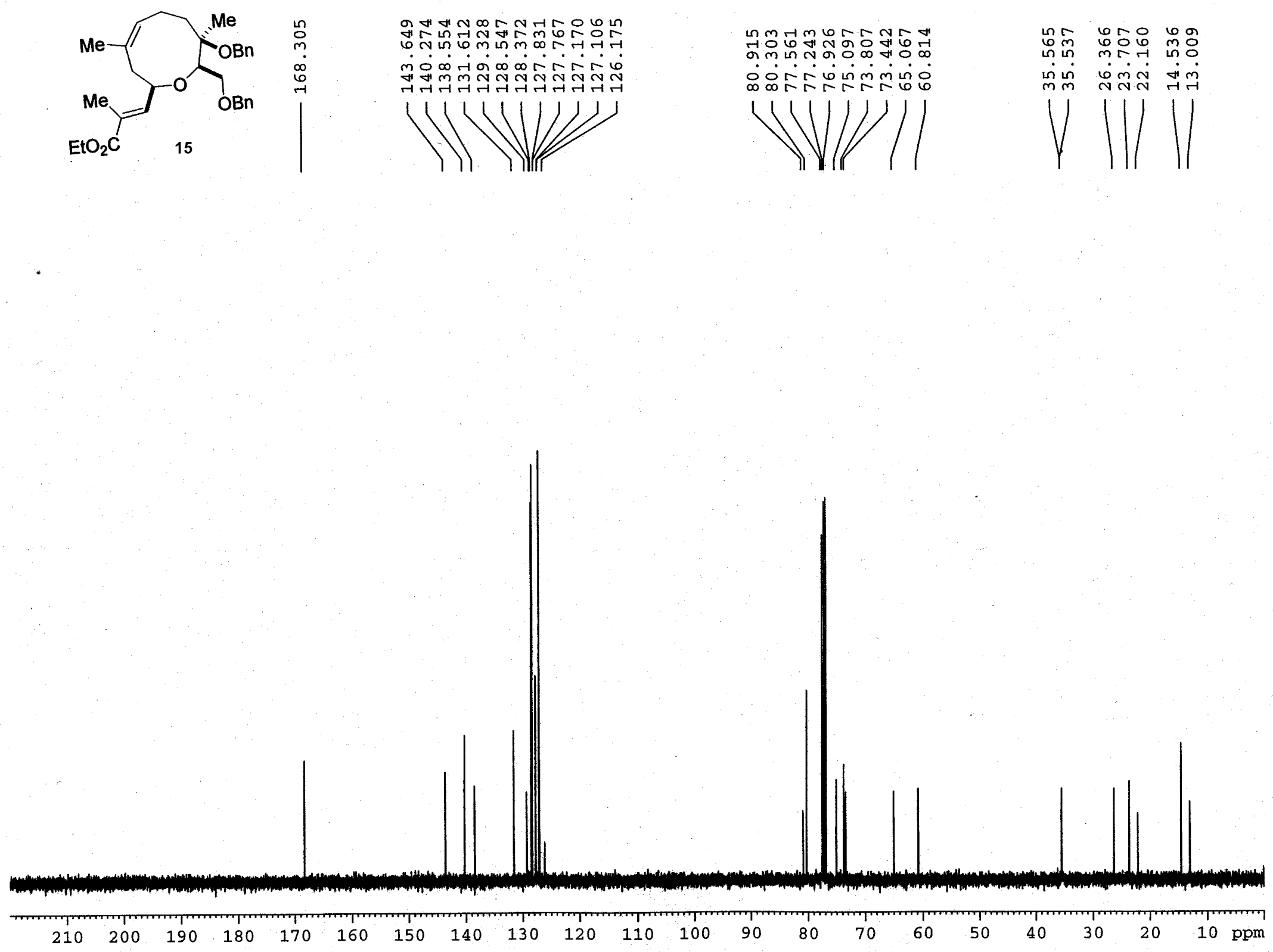


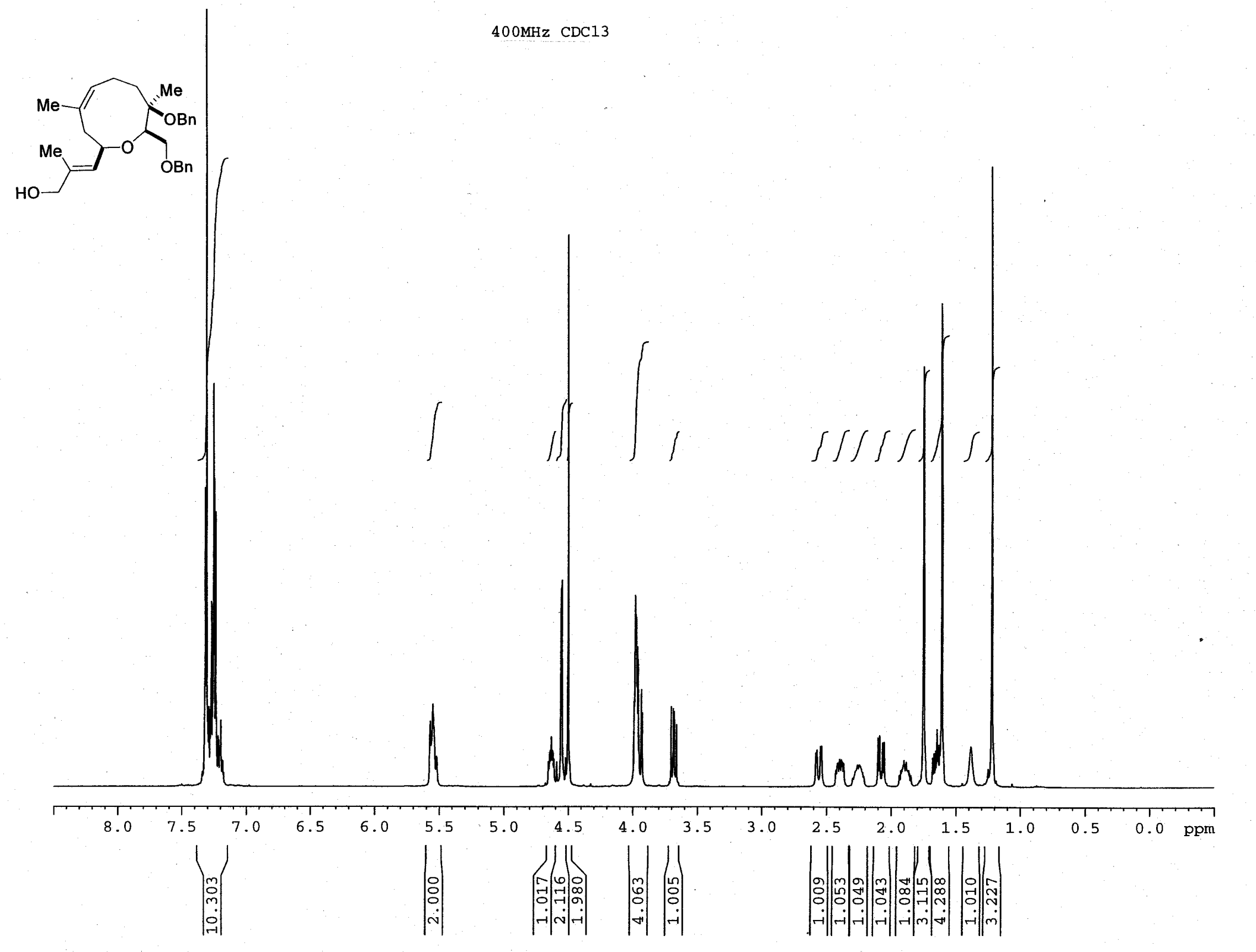


$100 \mathrm{MHz}$ CDC13
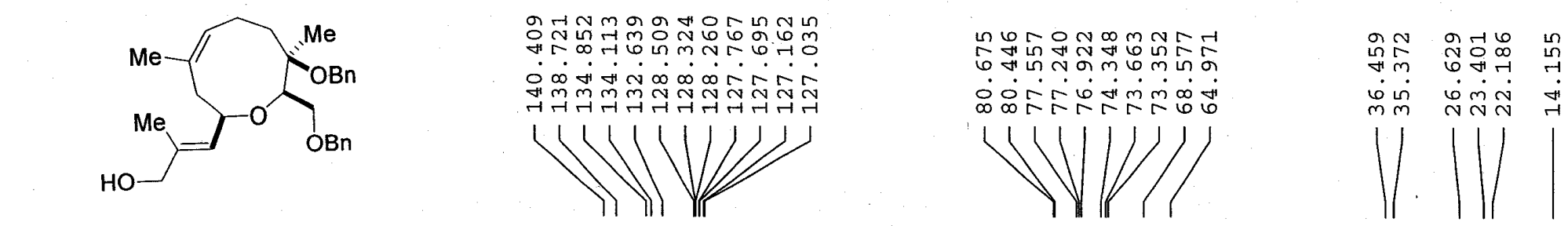
$400 \mathrm{MHz} \mathrm{CDCl} 3$

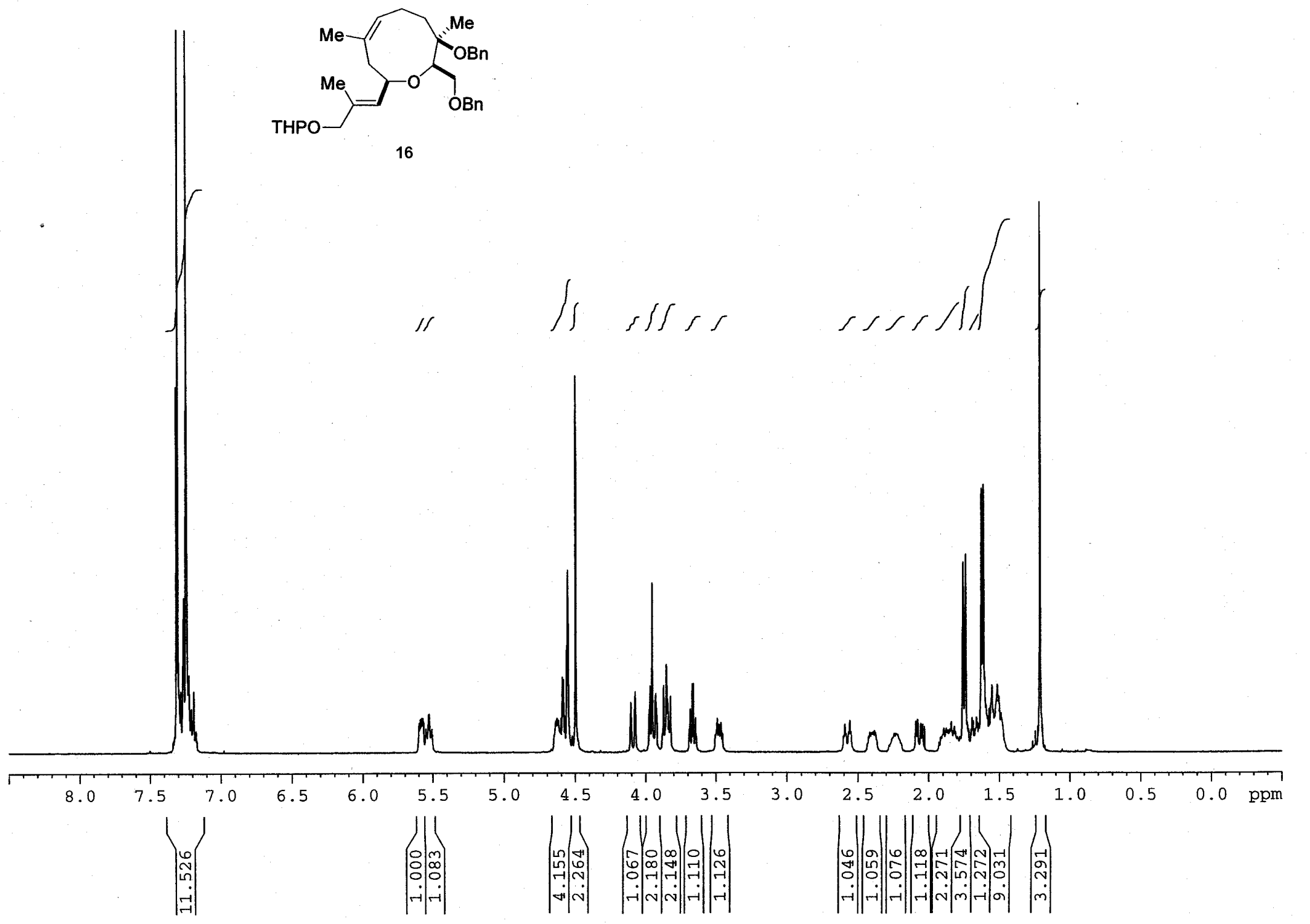


$100 \mathrm{MHz} \quad \mathrm{CDCl} 3$

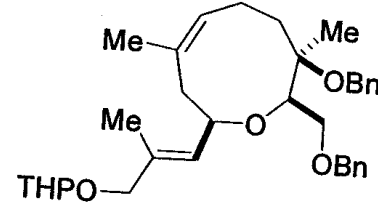

16

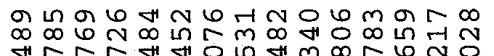

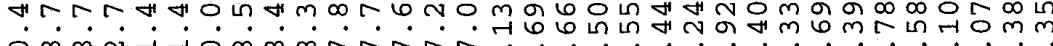

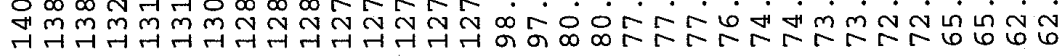

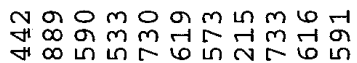
.

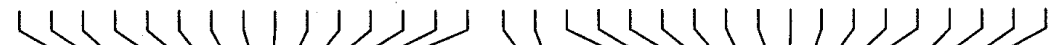

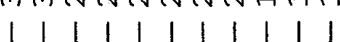

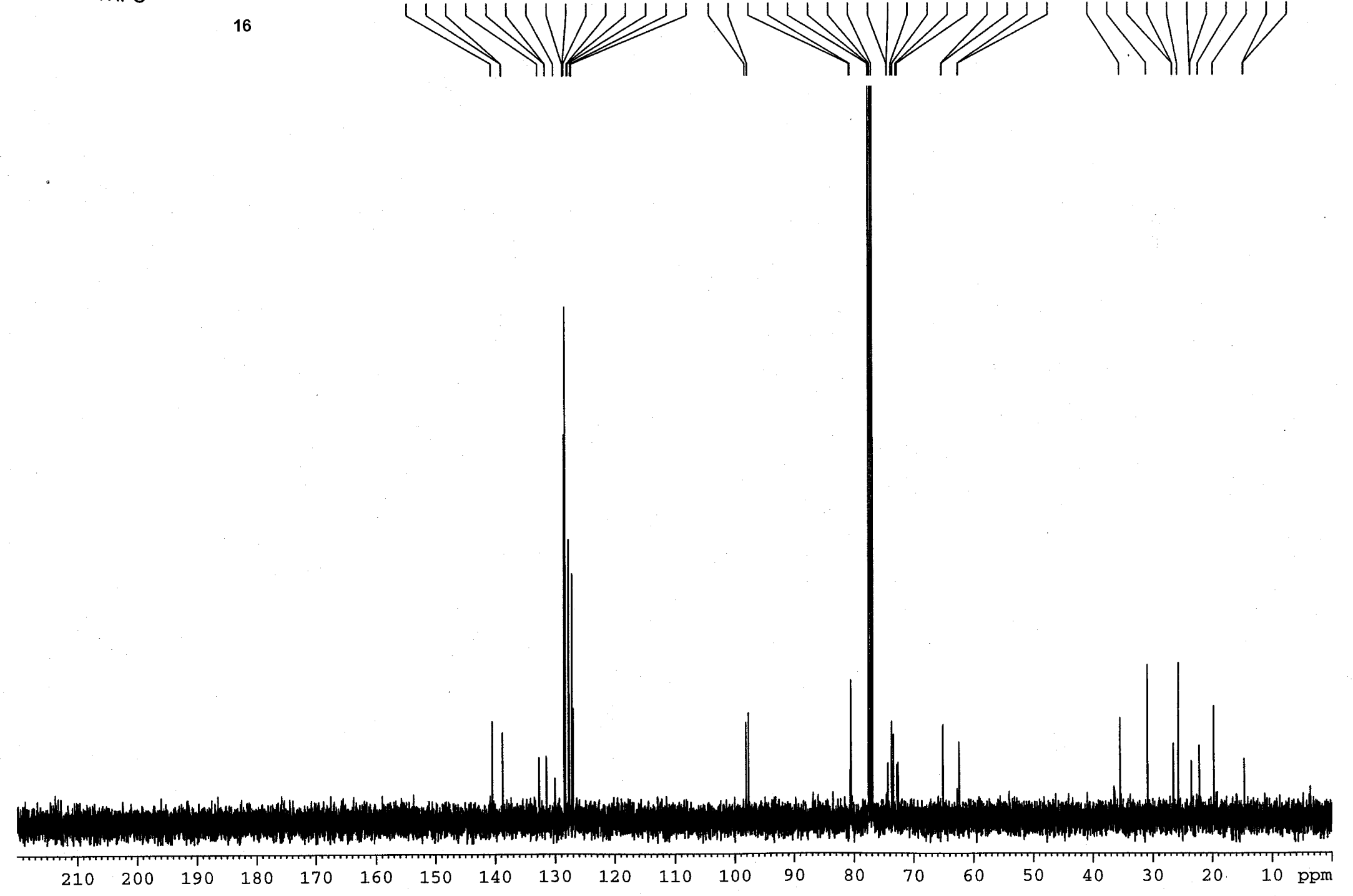

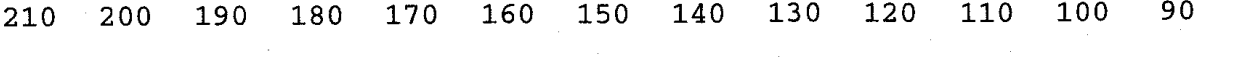


$400 \mathrm{MHz} \mathrm{CDCl} 3$

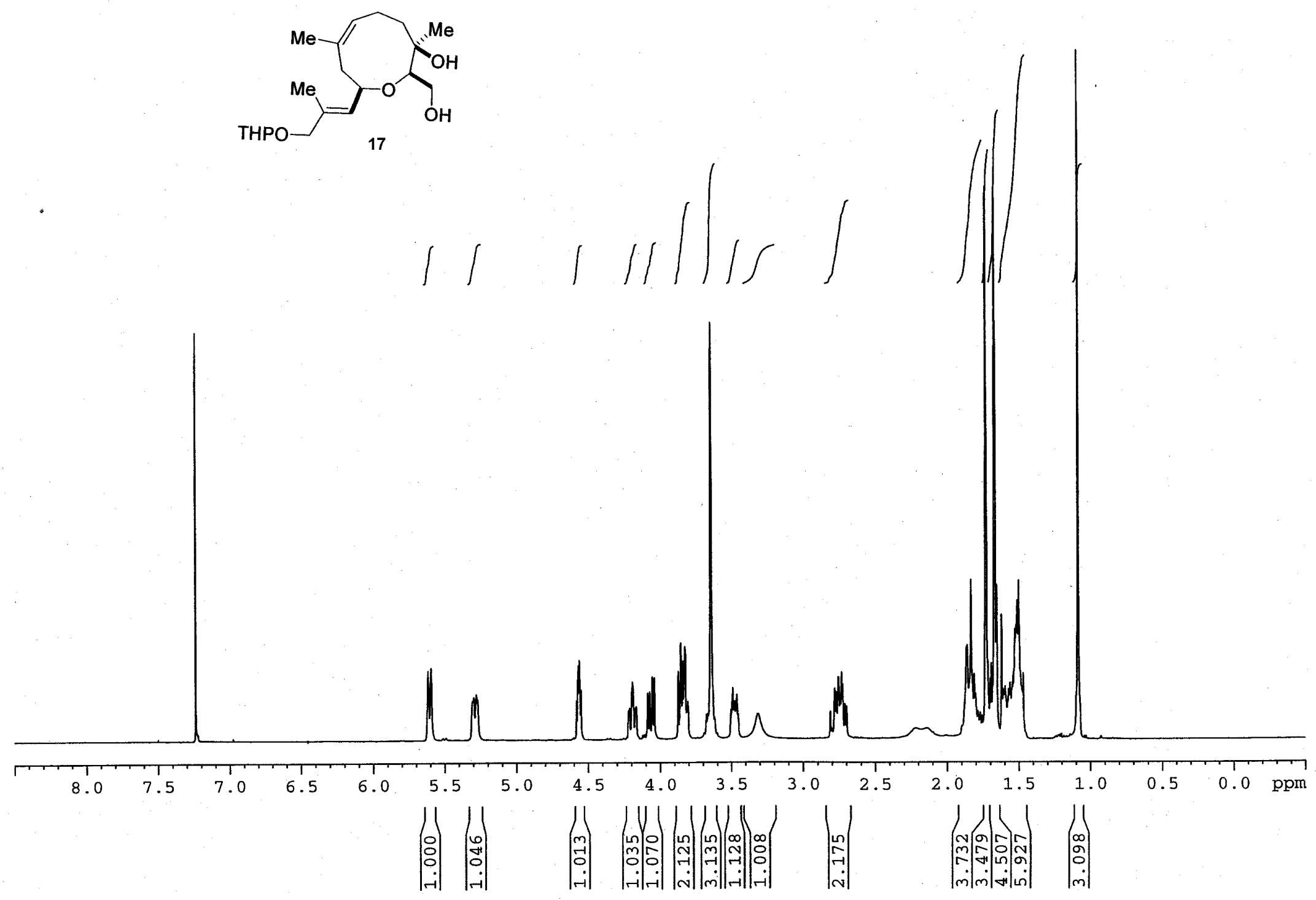


$100 \mathrm{MHz} \mathrm{CDC} 13$

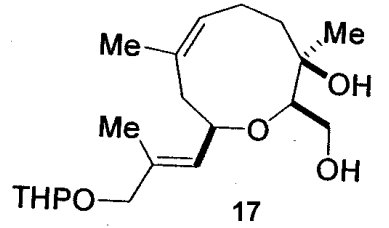

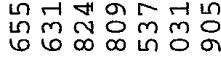

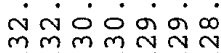

नमतनमत

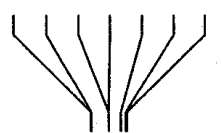

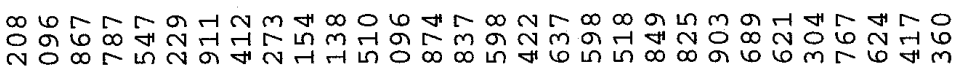
の o
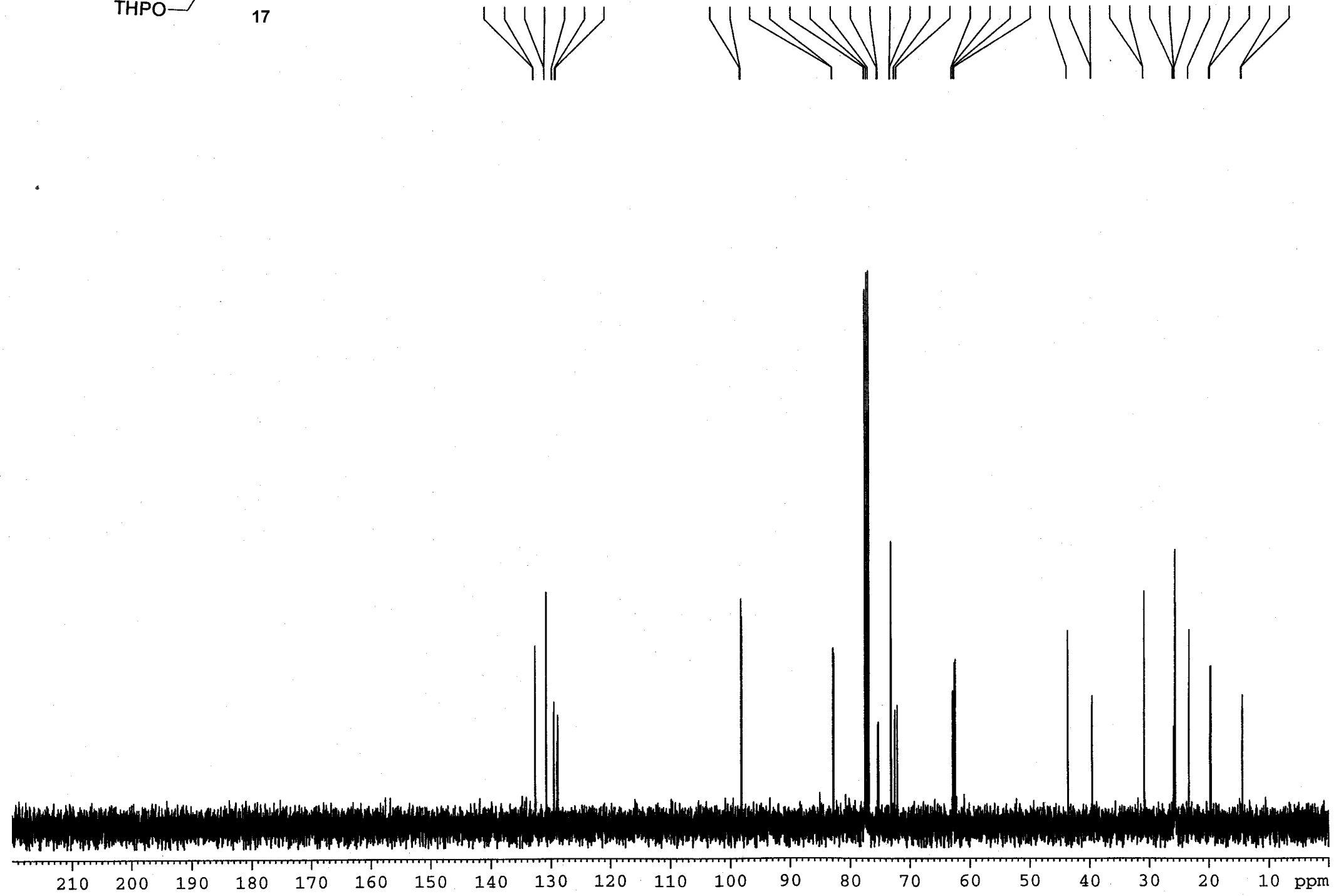


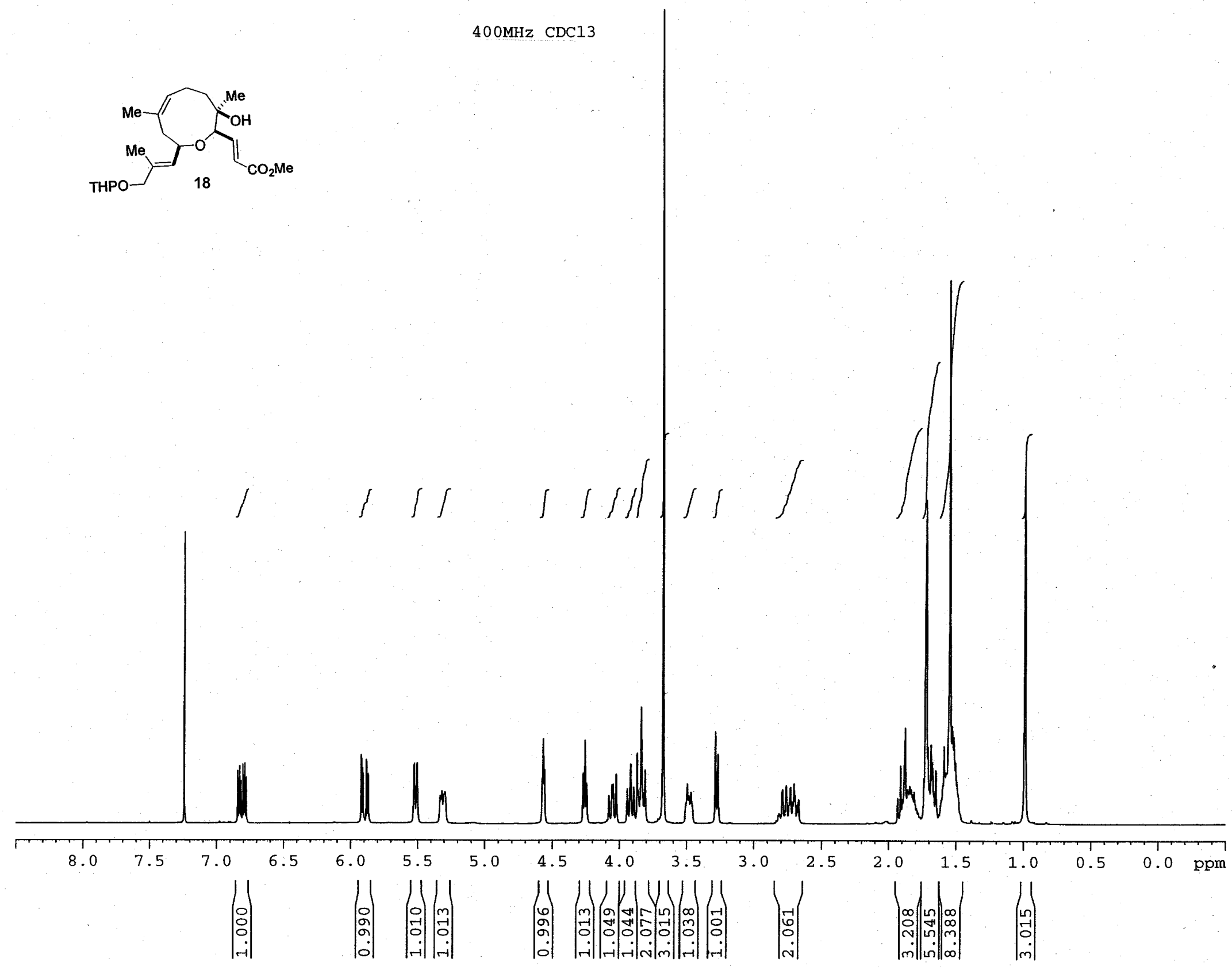


$100 \mathrm{MHz} \operatorname{CDCl} 3$
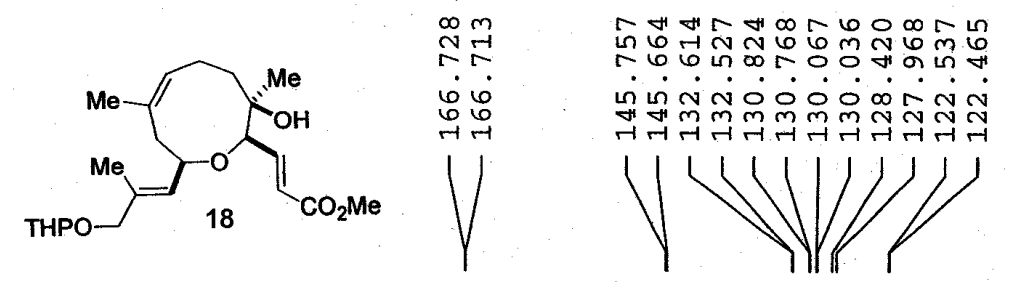

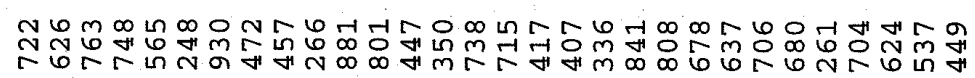

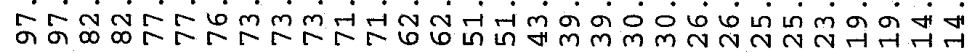
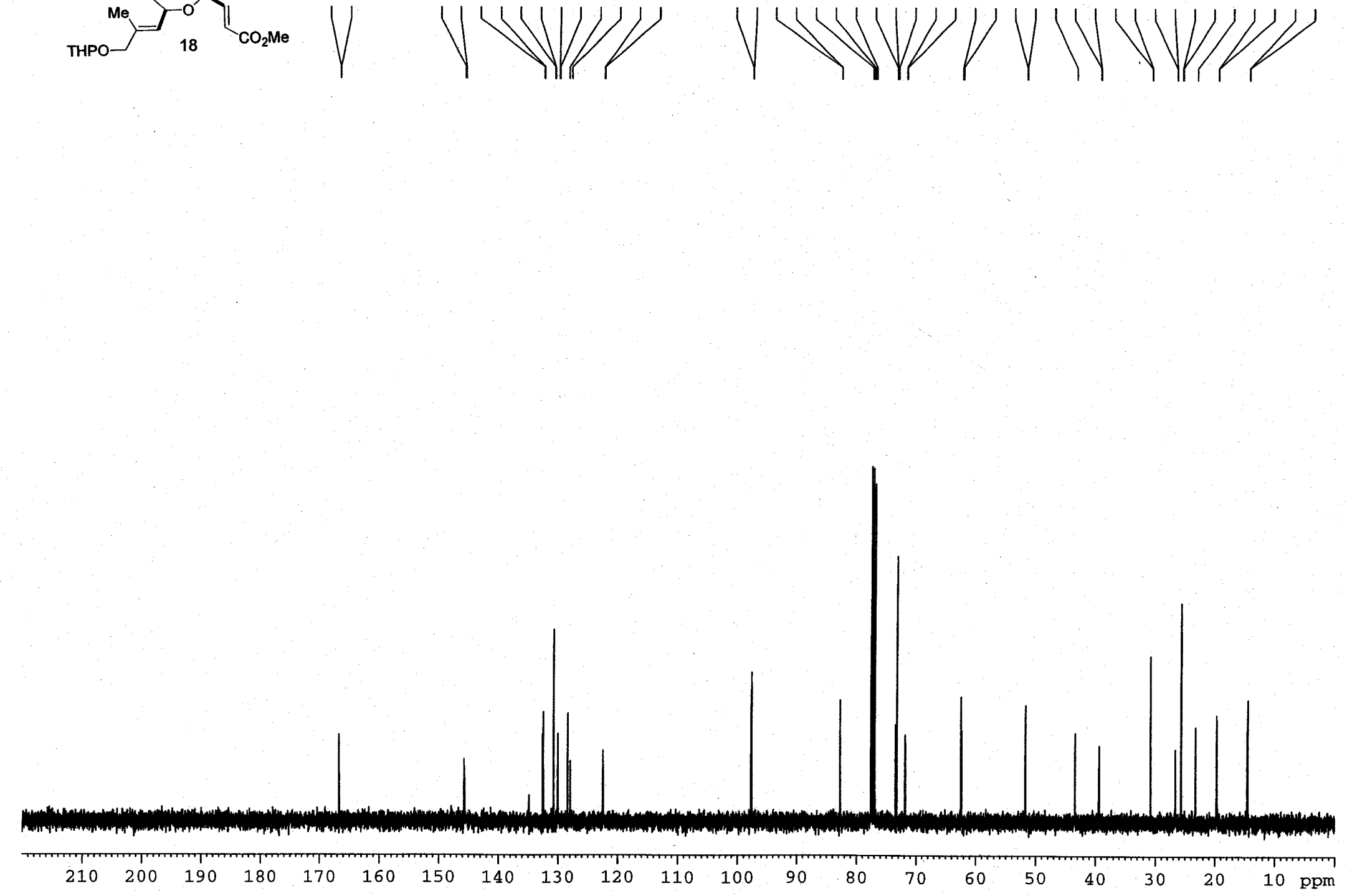
$400 \mathrm{MHz} \quad \mathrm{CDCl} 3$

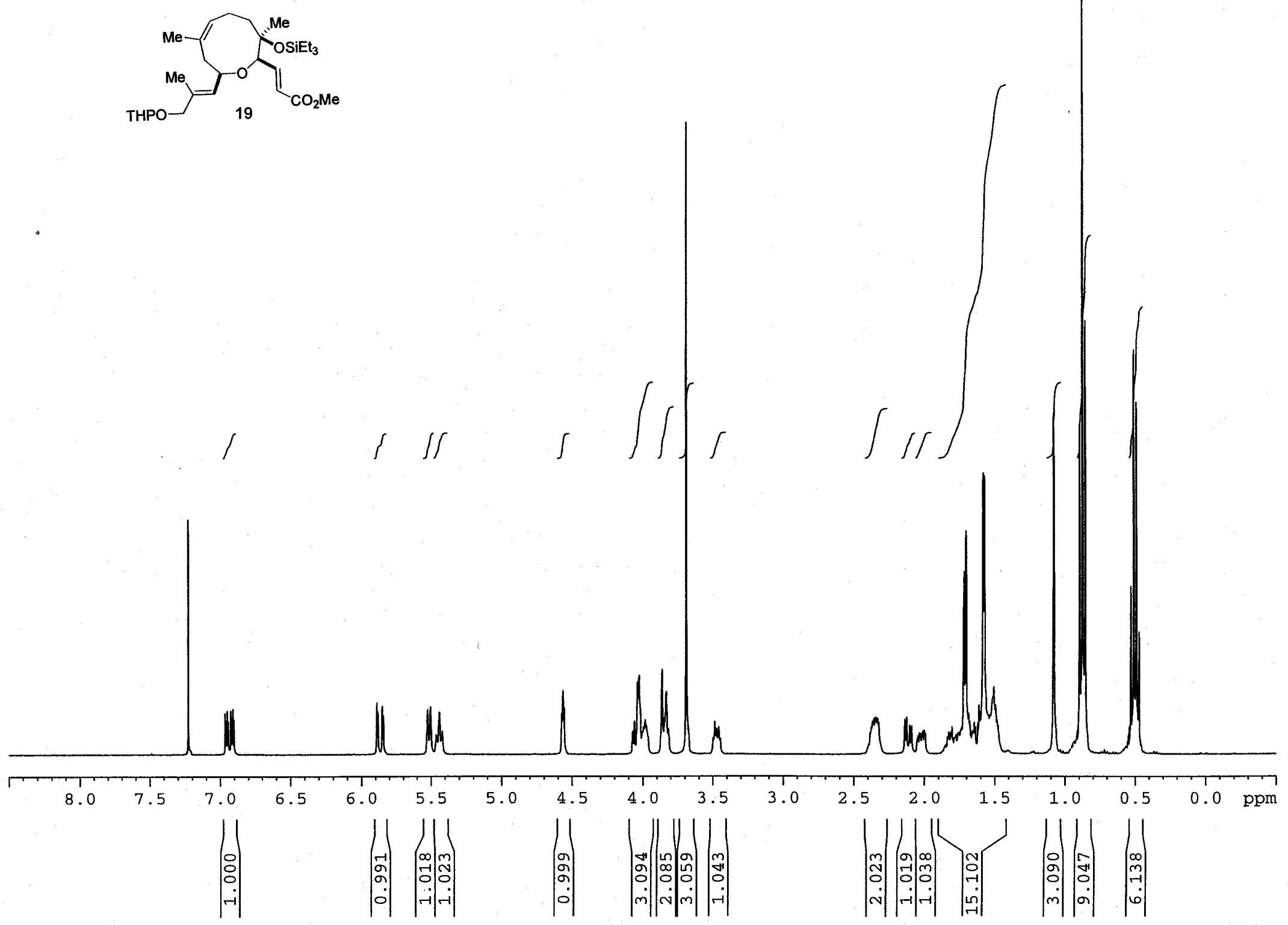


$100 \mathrm{MHz} \mathrm{CDCl} 3$

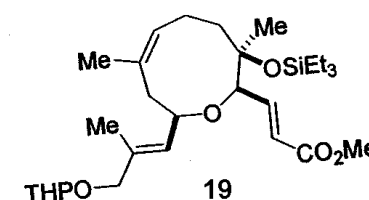

$$
\begin{aligned}
& 0 \\
& \frac{0}{2} \\
& 0 \\
& 0 \\
& 0 \\
& 1 \\
& 1
\end{aligned}
$$

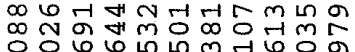

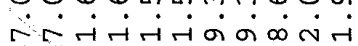

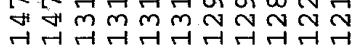

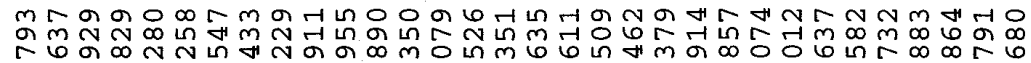

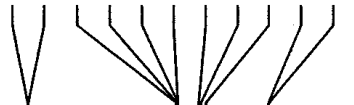

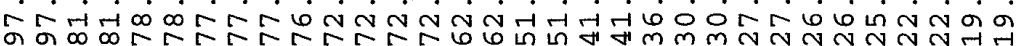
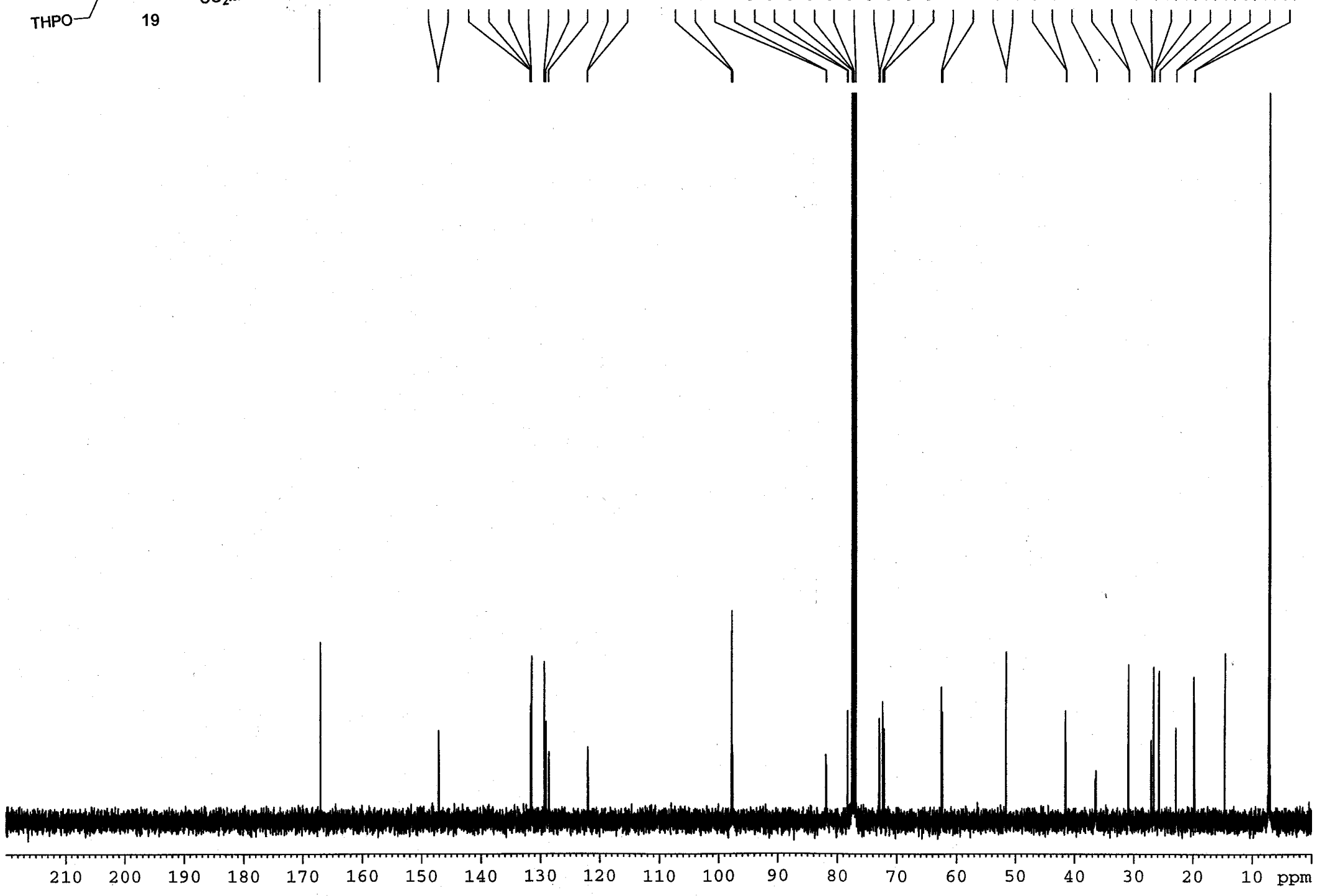


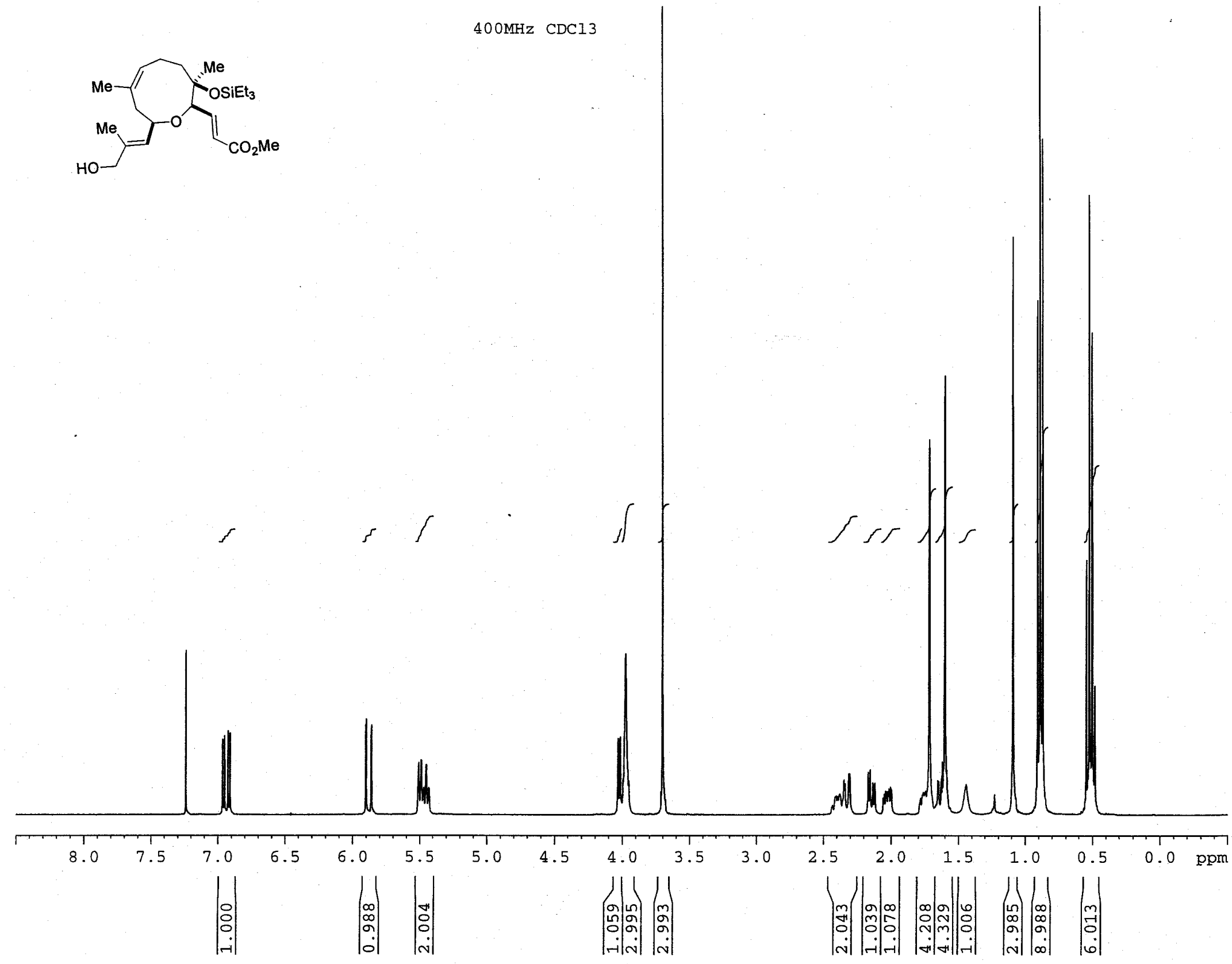


$100 \mathrm{MHz} \mathrm{CDCl} 3$
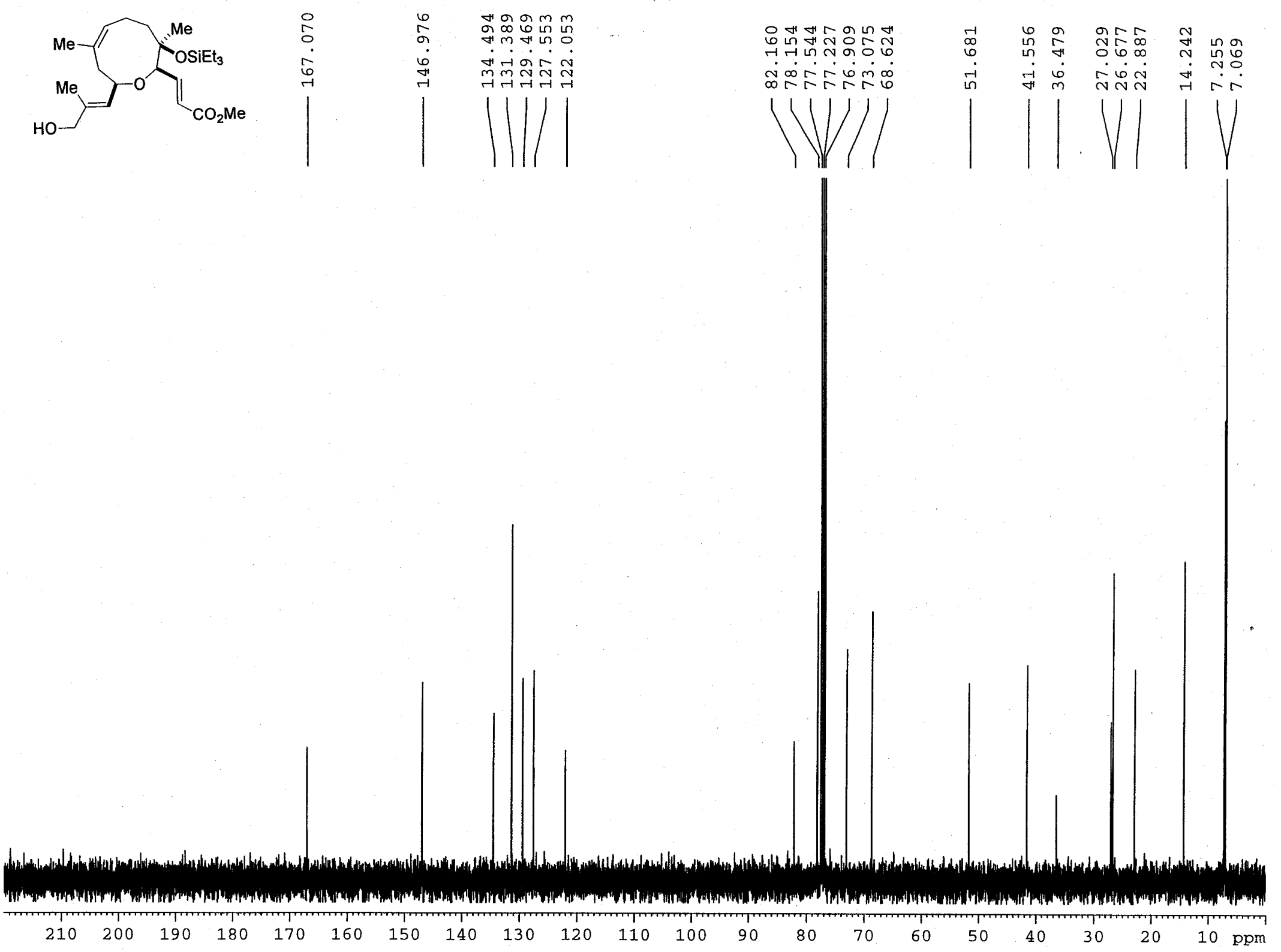


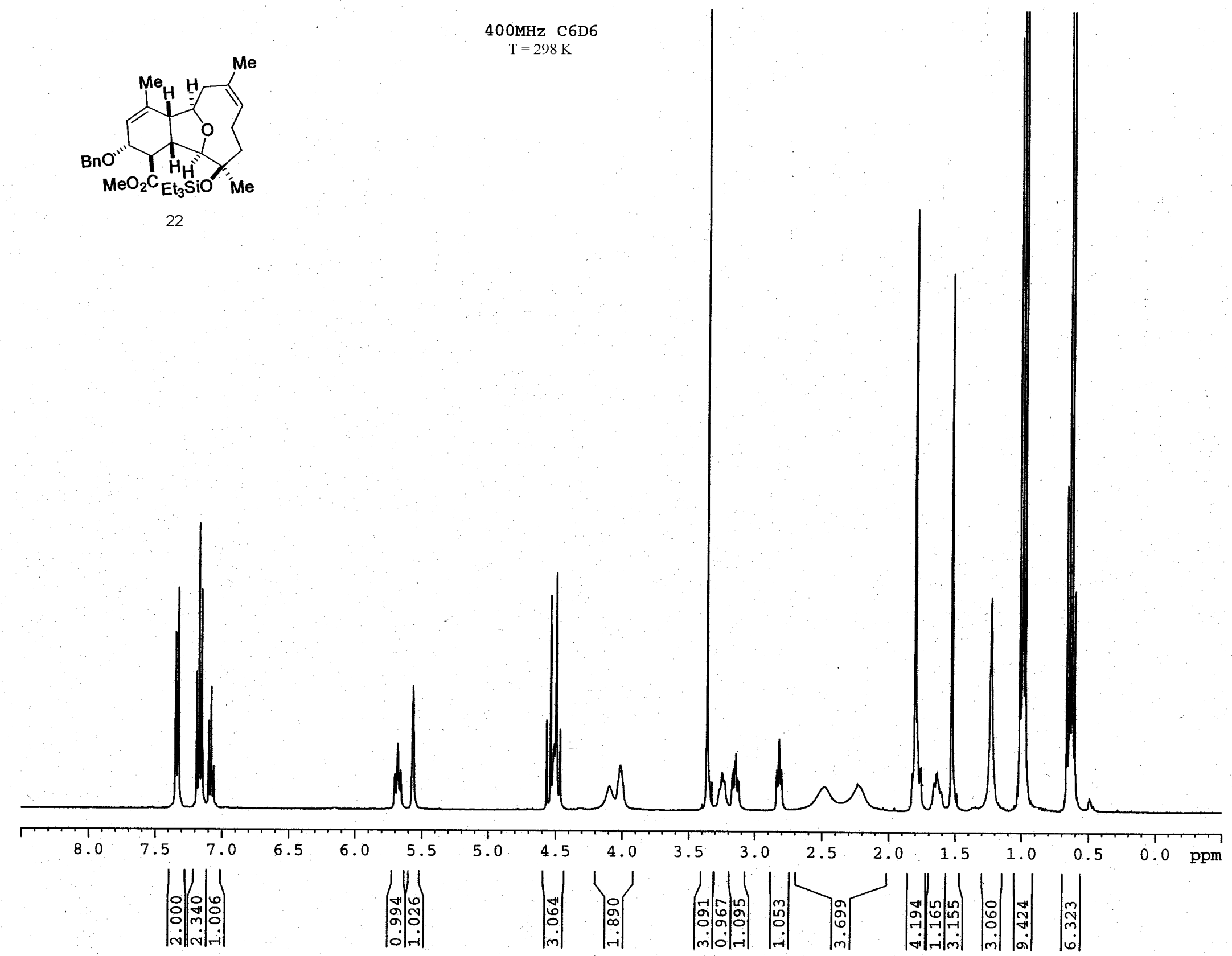




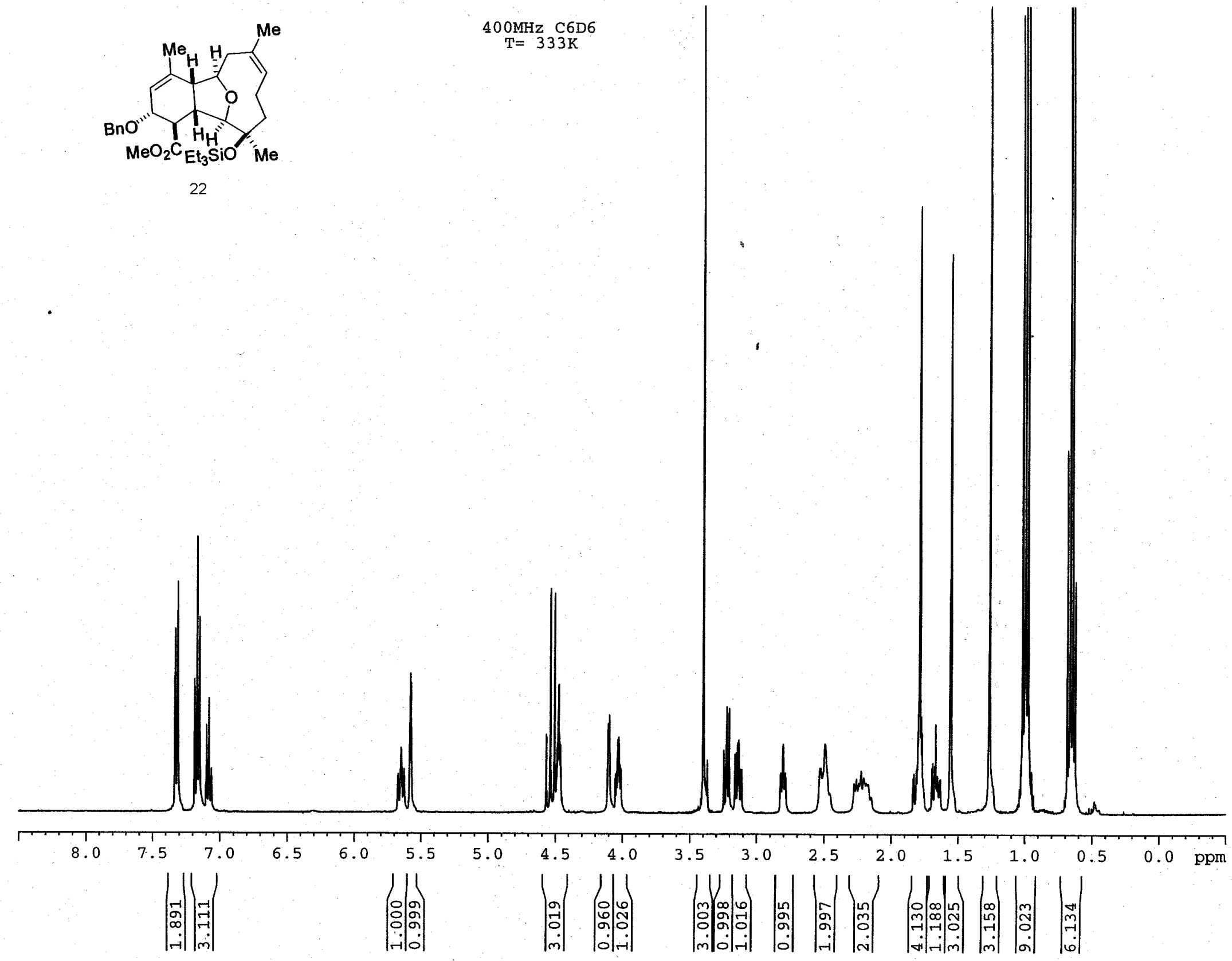


$100 \mathrm{MHz} \operatorname{CDCl} 3 \mathrm{~T}=333 \mathrm{~K}$

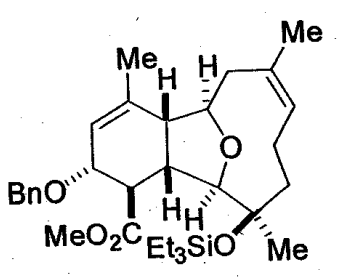

22
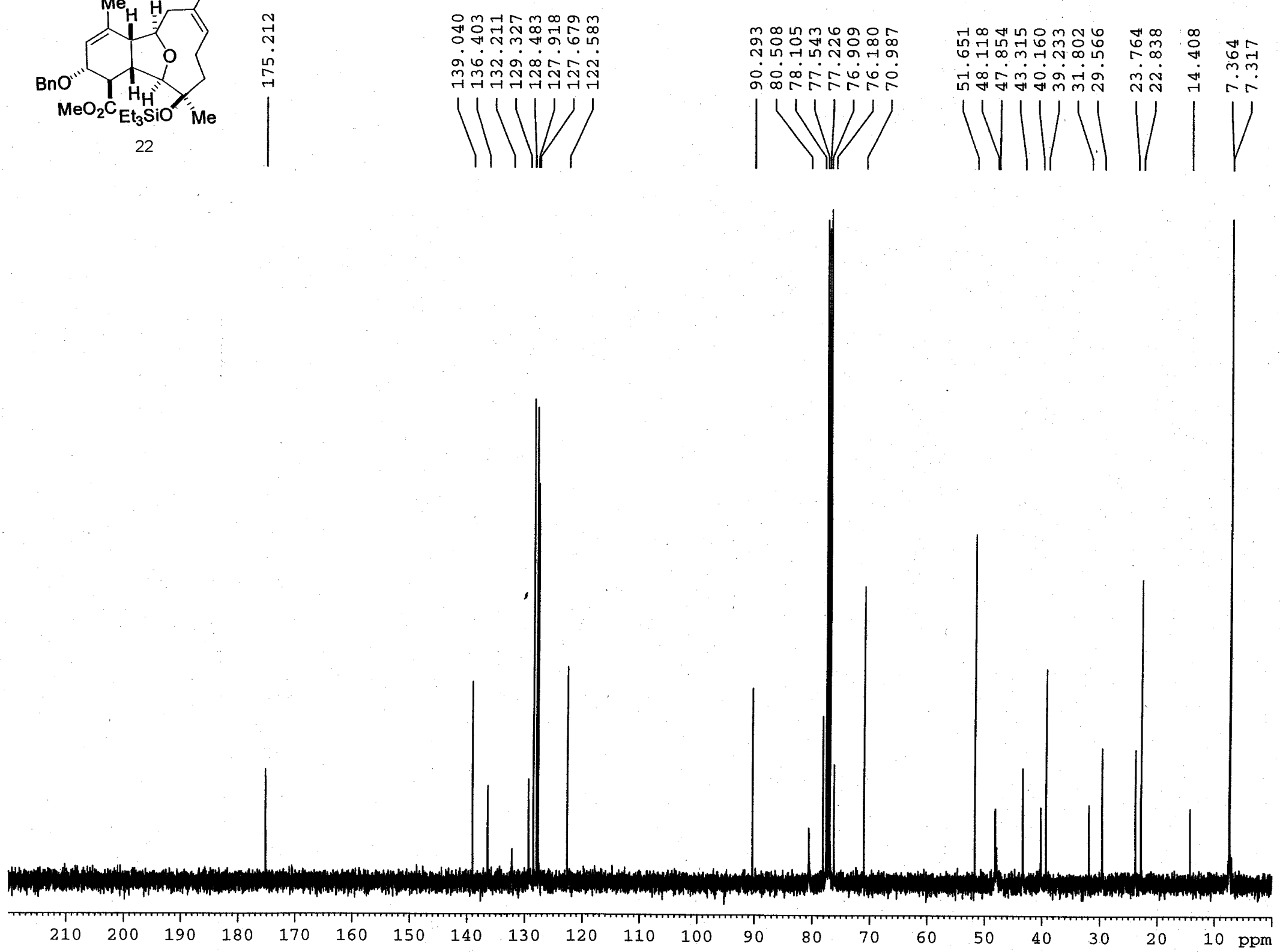
400MHz $\mathrm{CDCl} 3$
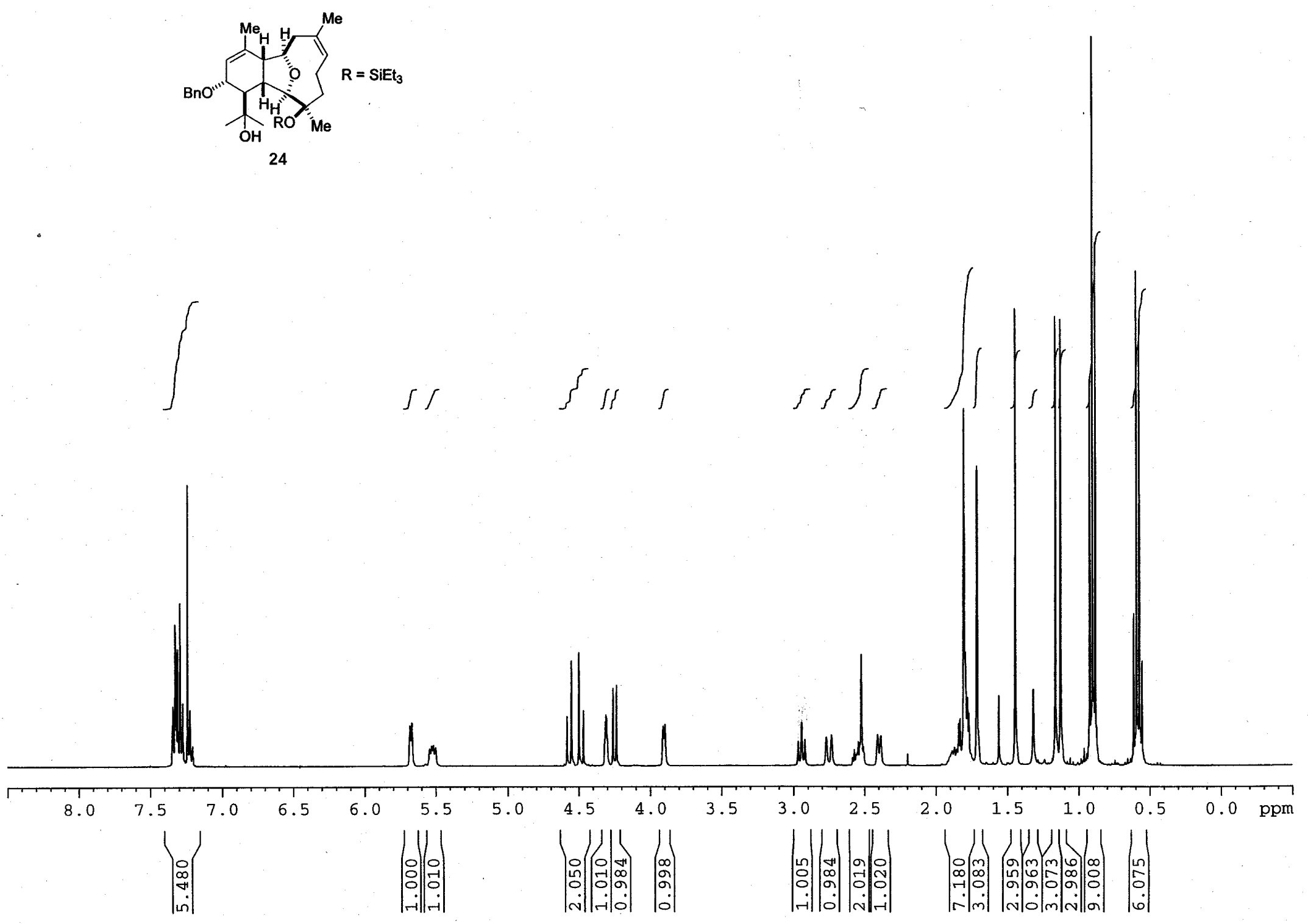
$100 \mathrm{MHz} \mathrm{CDC} 3$
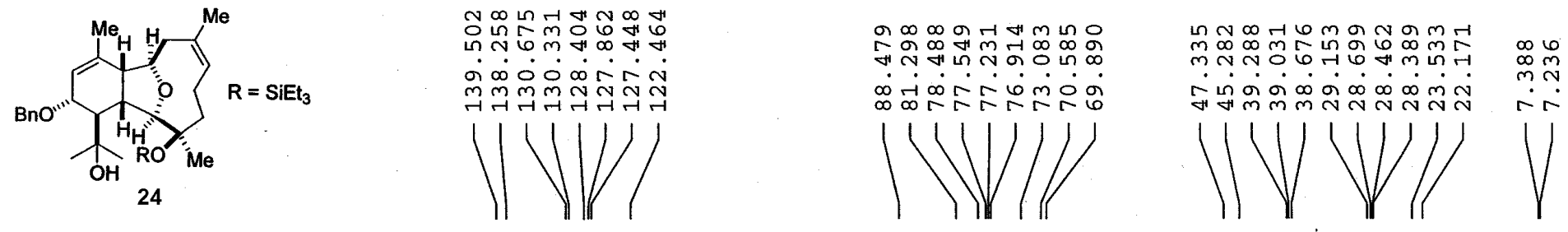

24

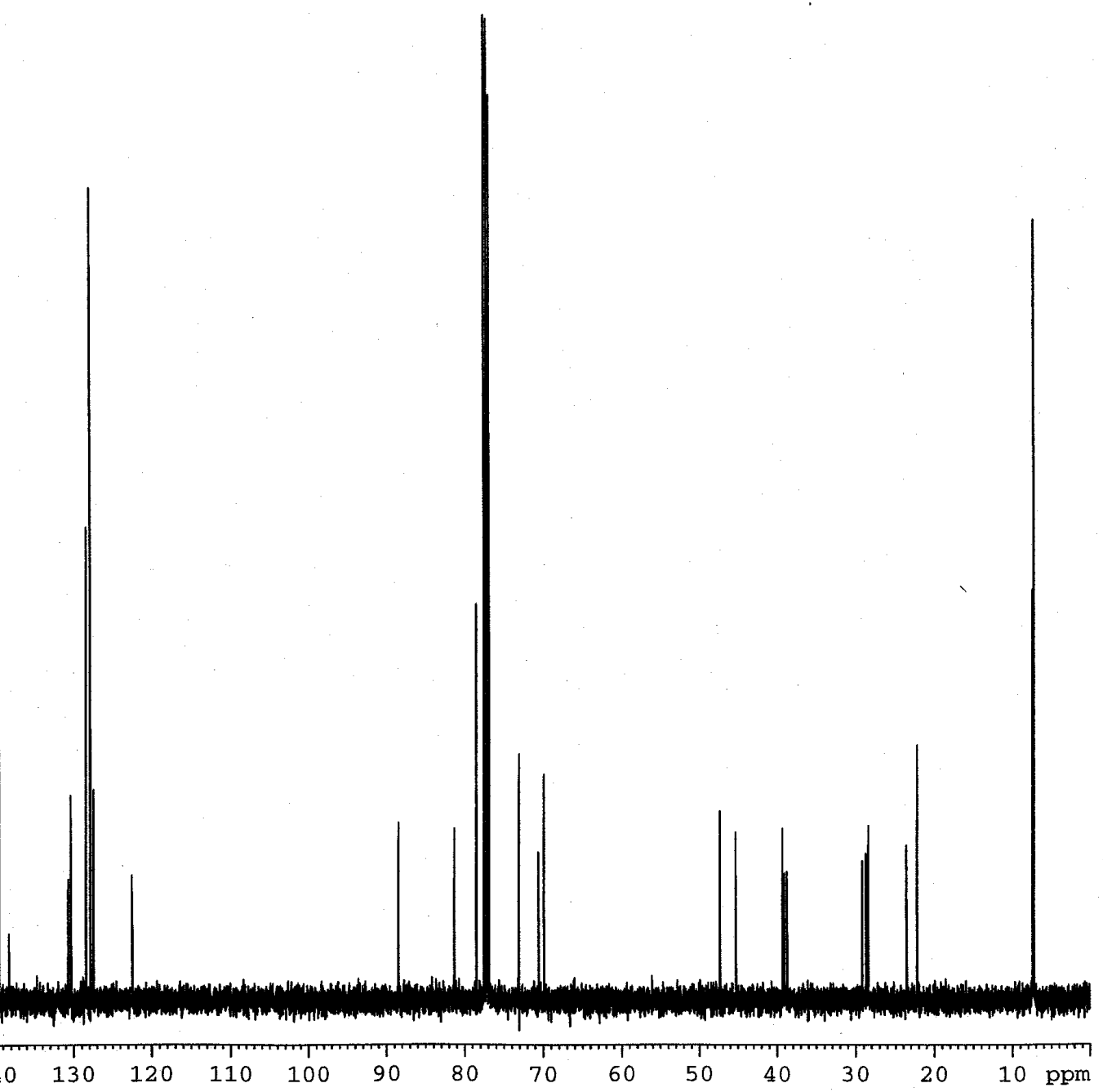




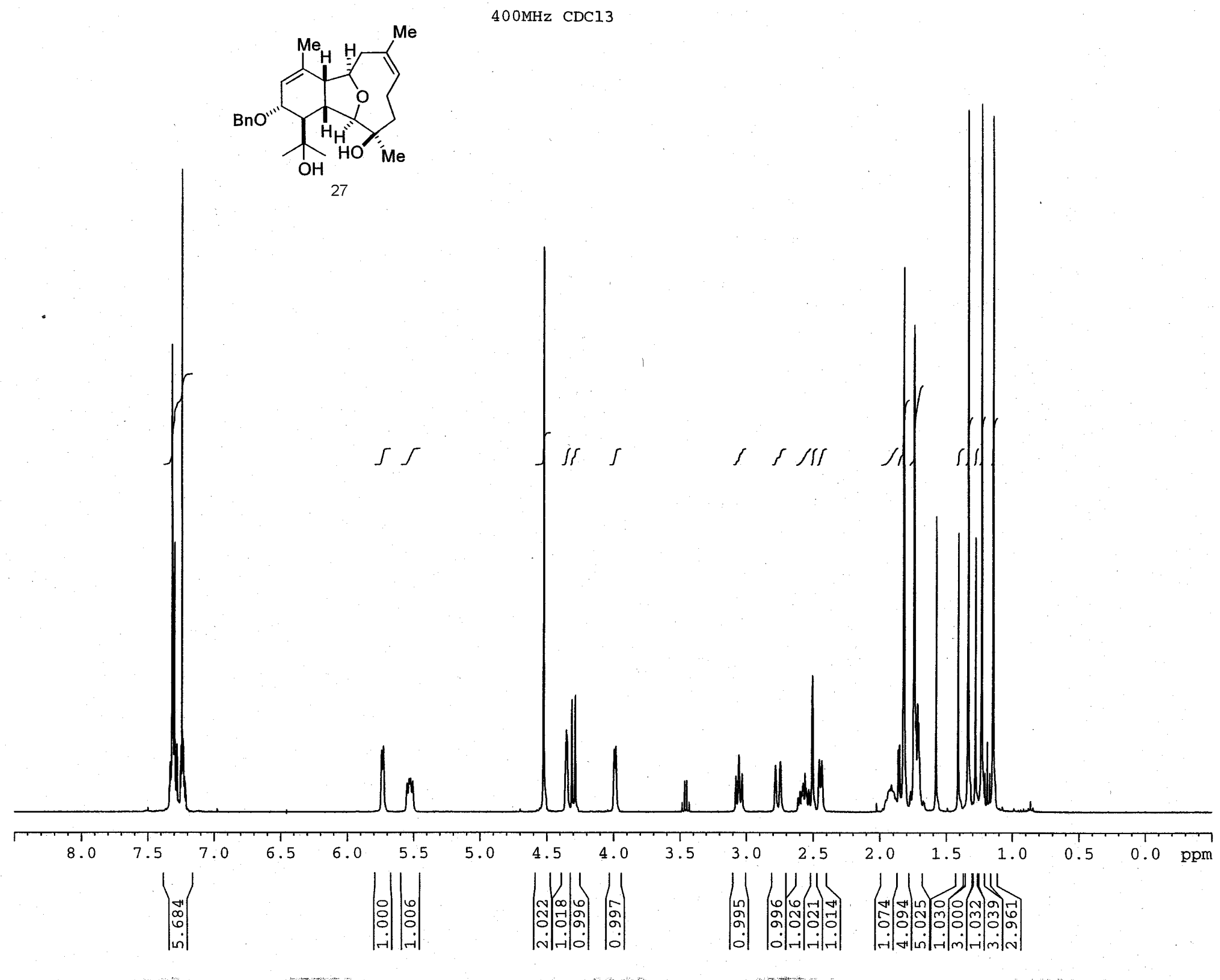


100MHz CDDCl3

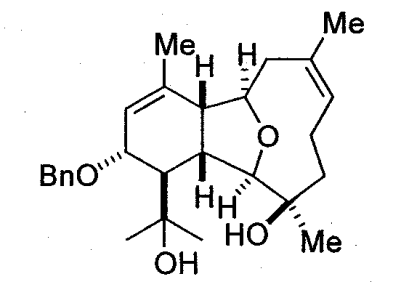

27

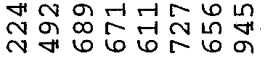
mpoiman

न

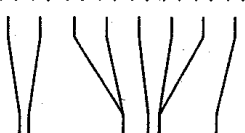

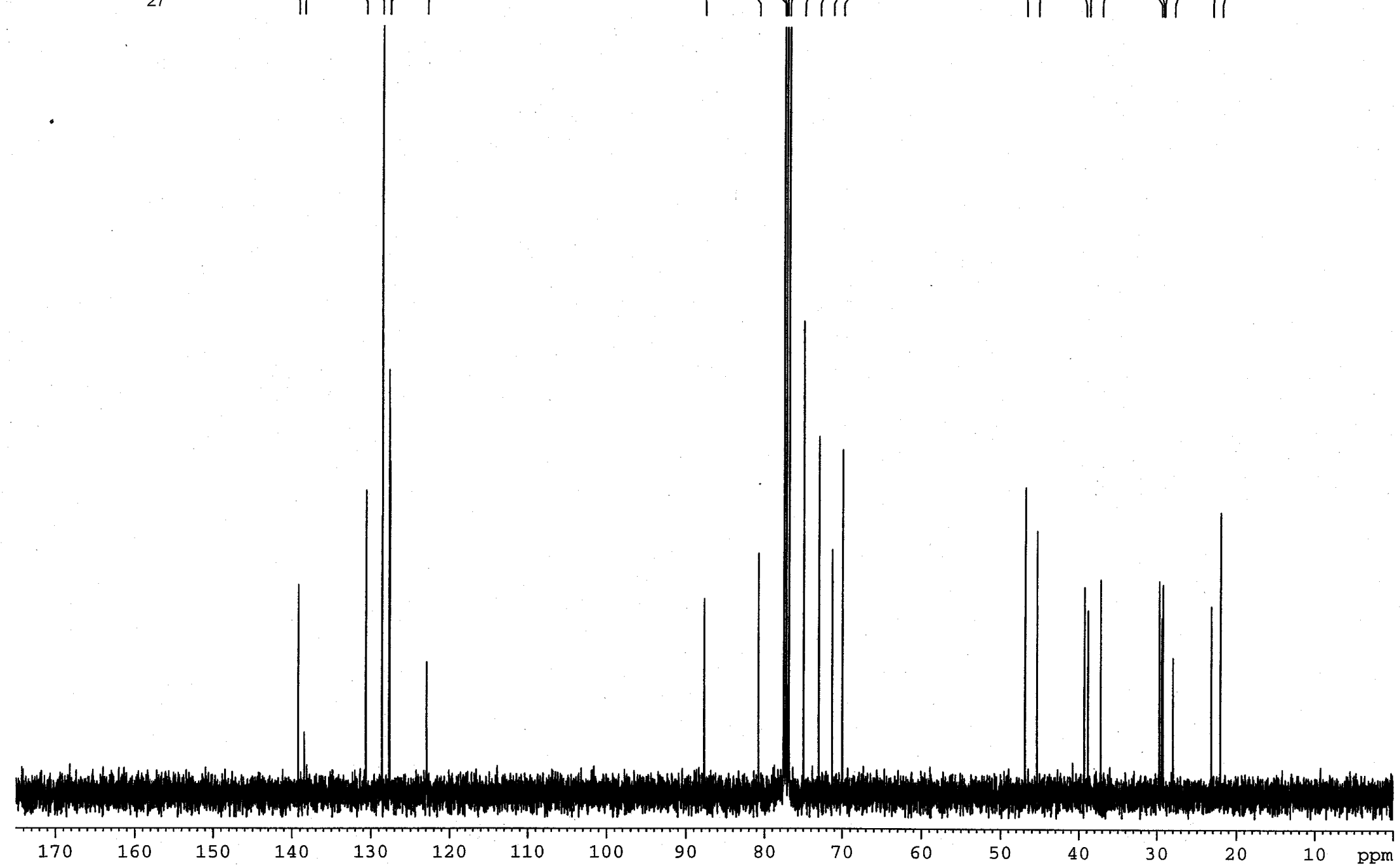


$400 \mathrm{MHz}$ CDC13
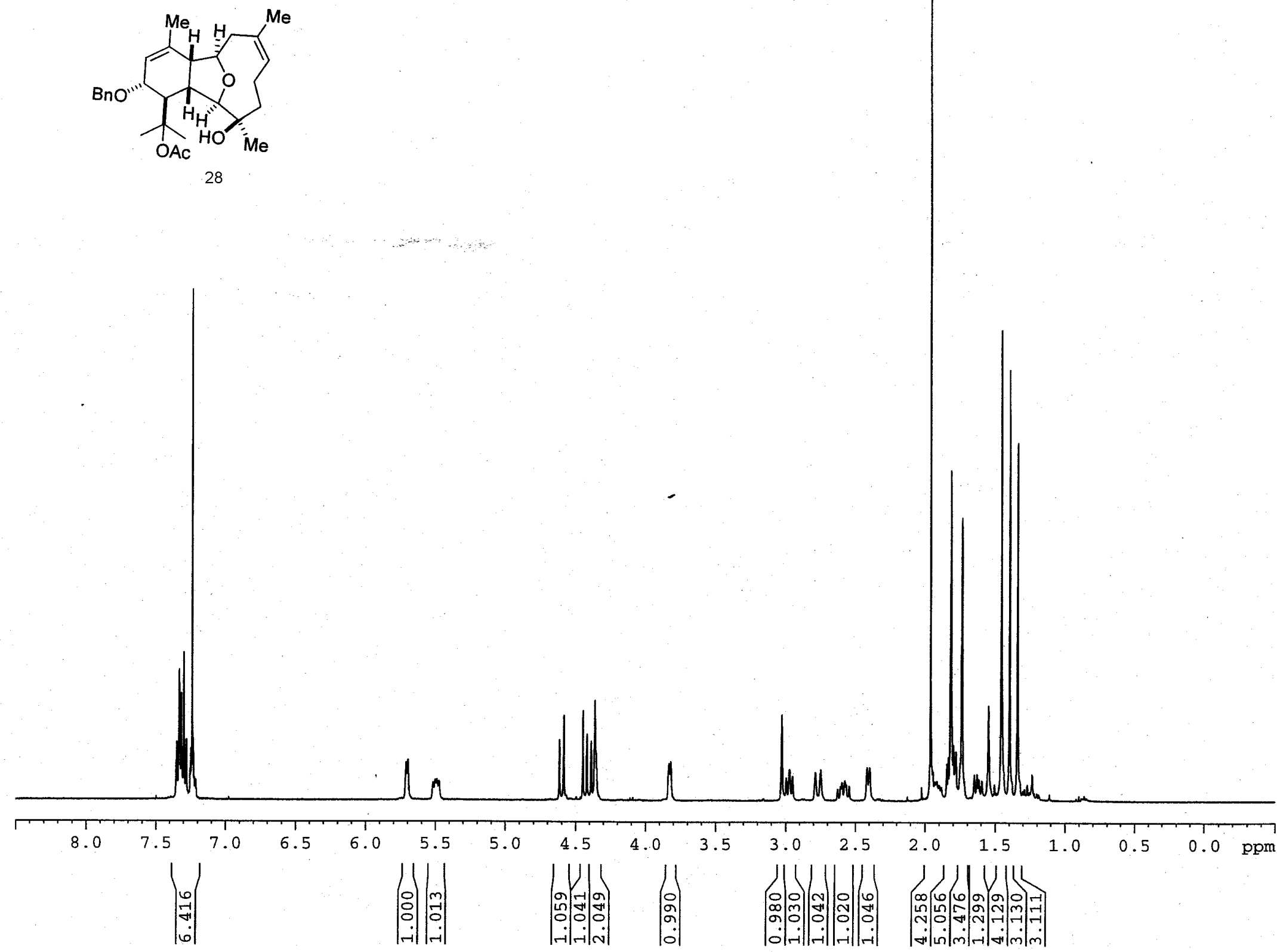
100MHz $\mathrm{CDCl} 3$
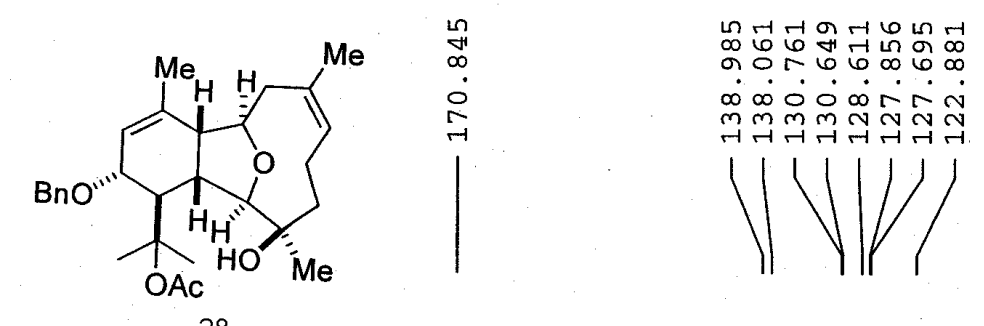

28
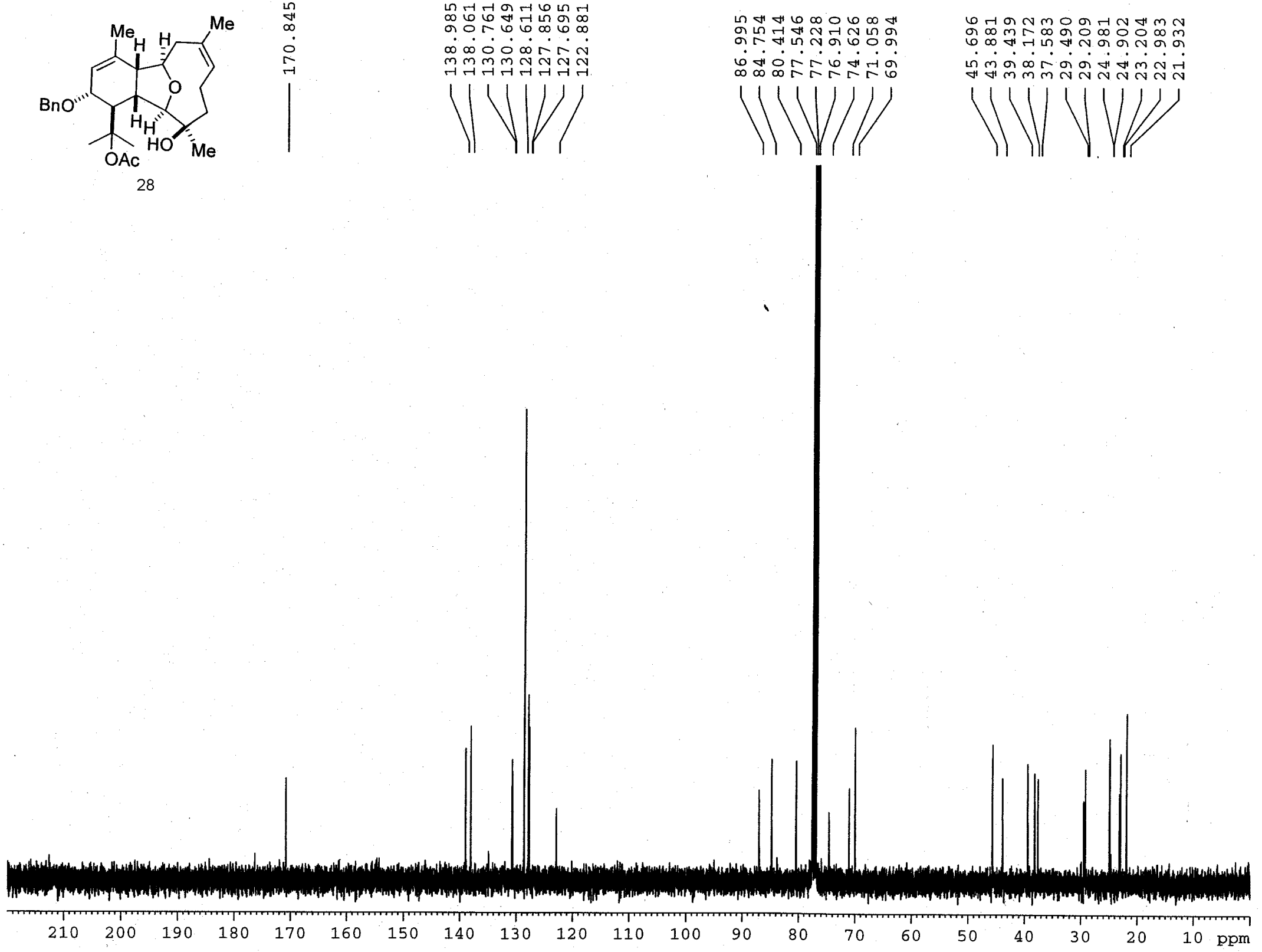


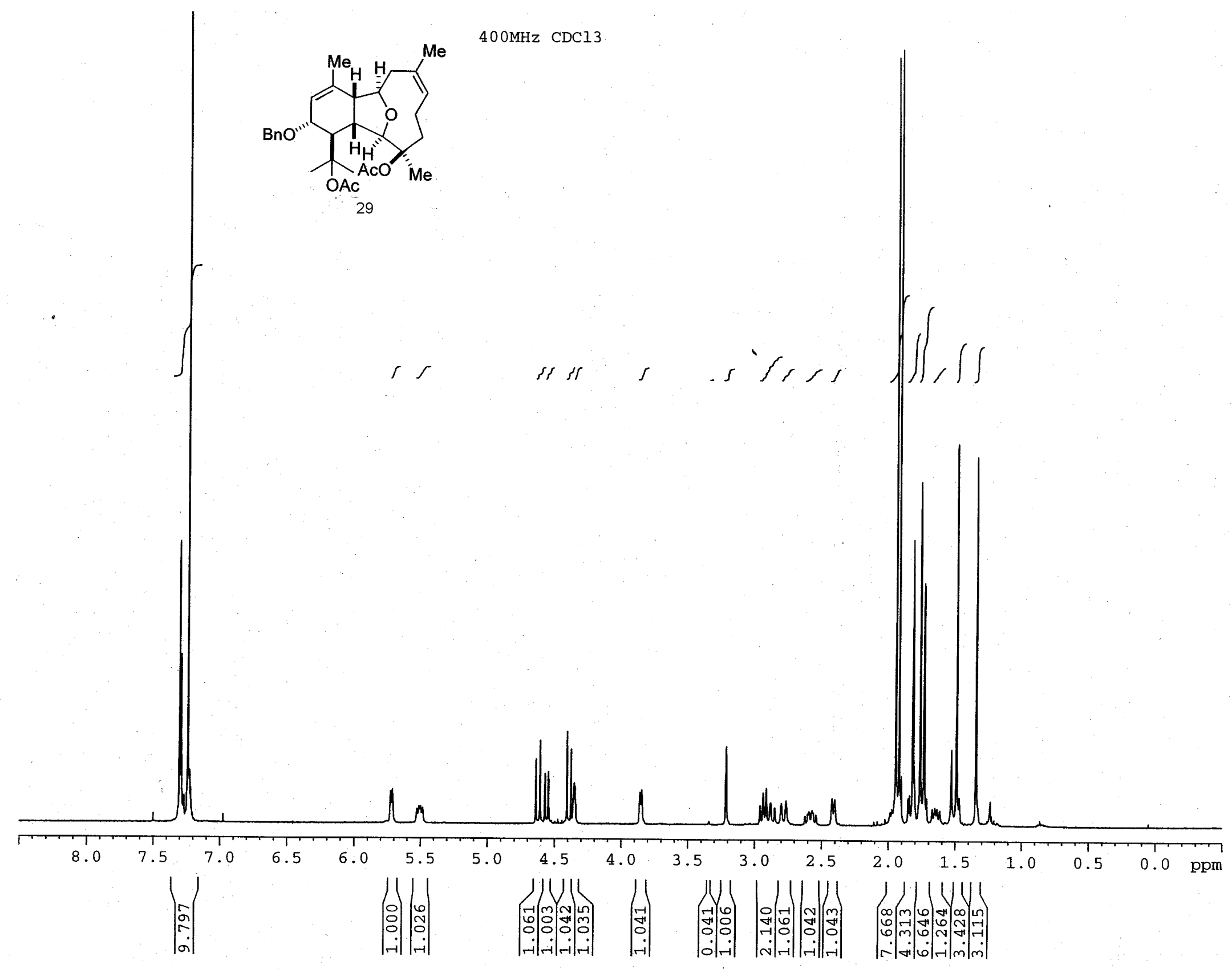


100MHz $\mathrm{CDCl}$
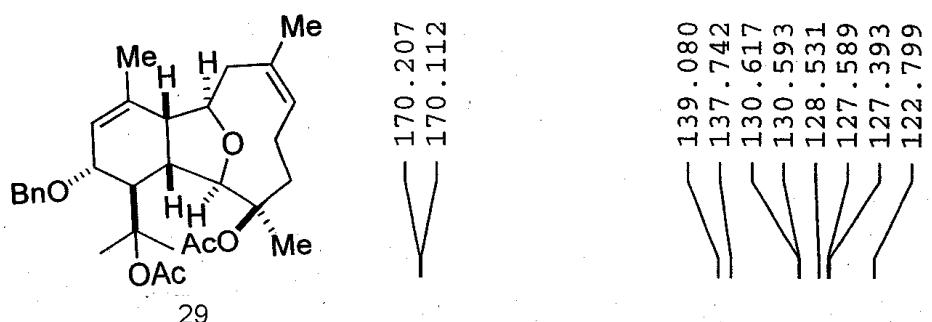

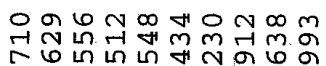

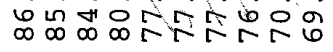

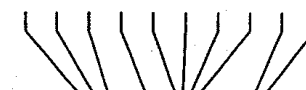

29

H

传

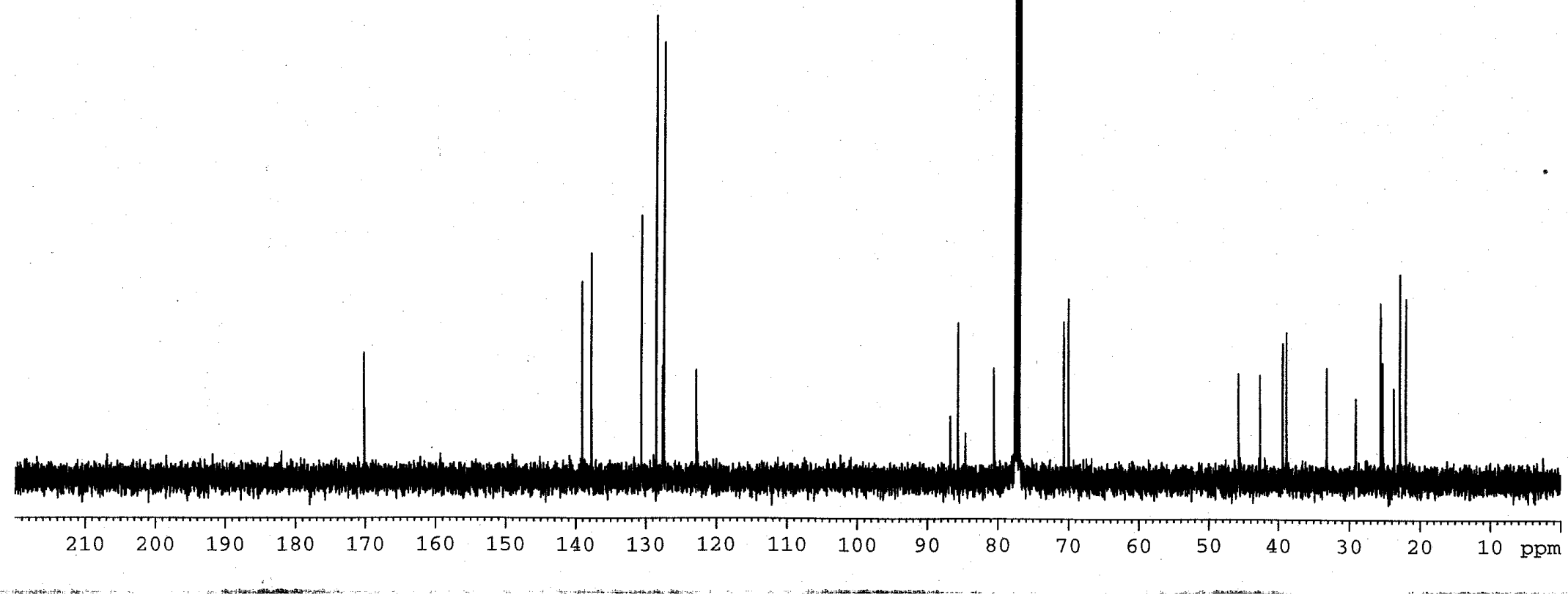


$500 \mathrm{MHz}$ CDC13

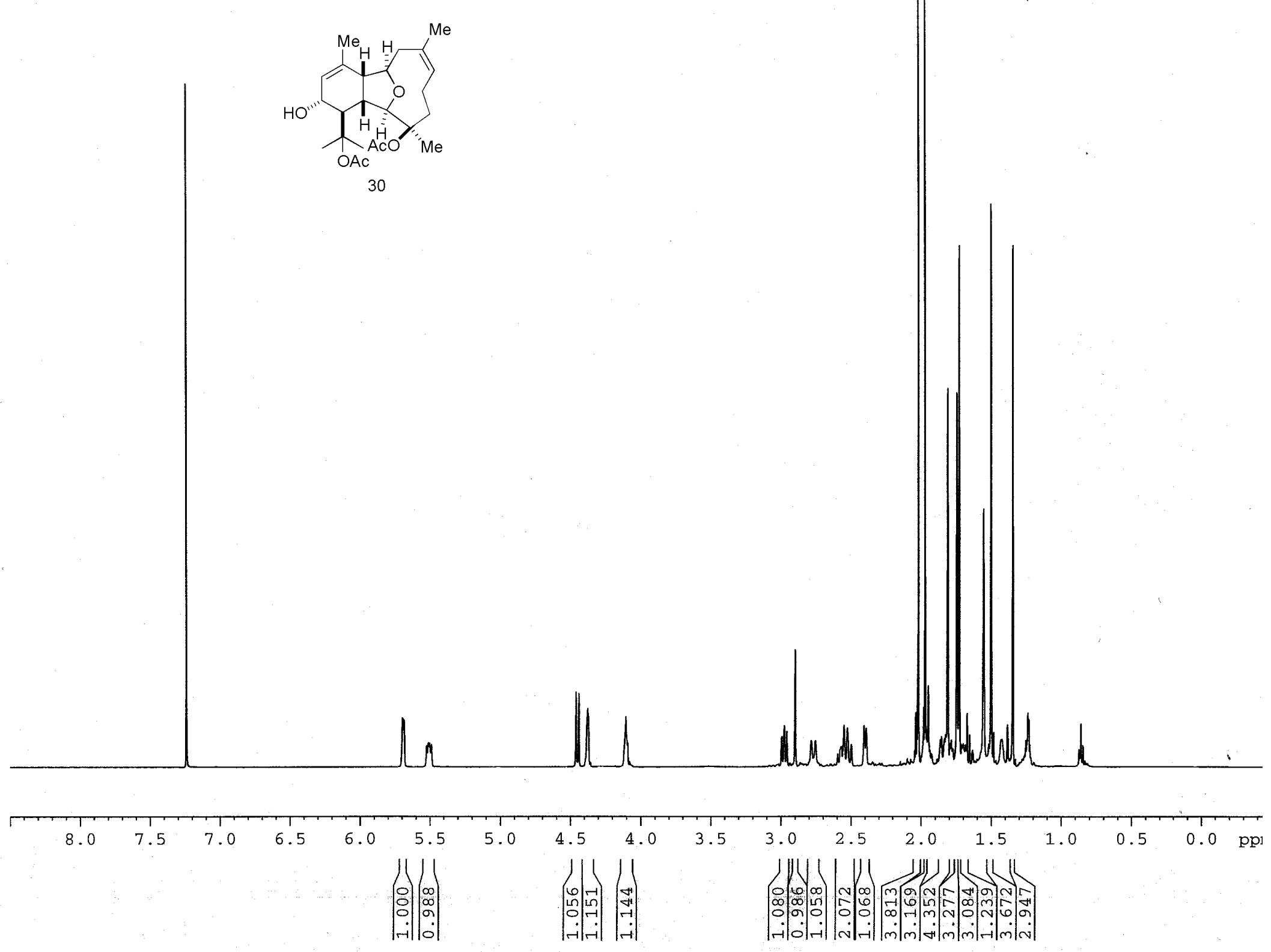


$125 \mathrm{MHz}$ CDCl3
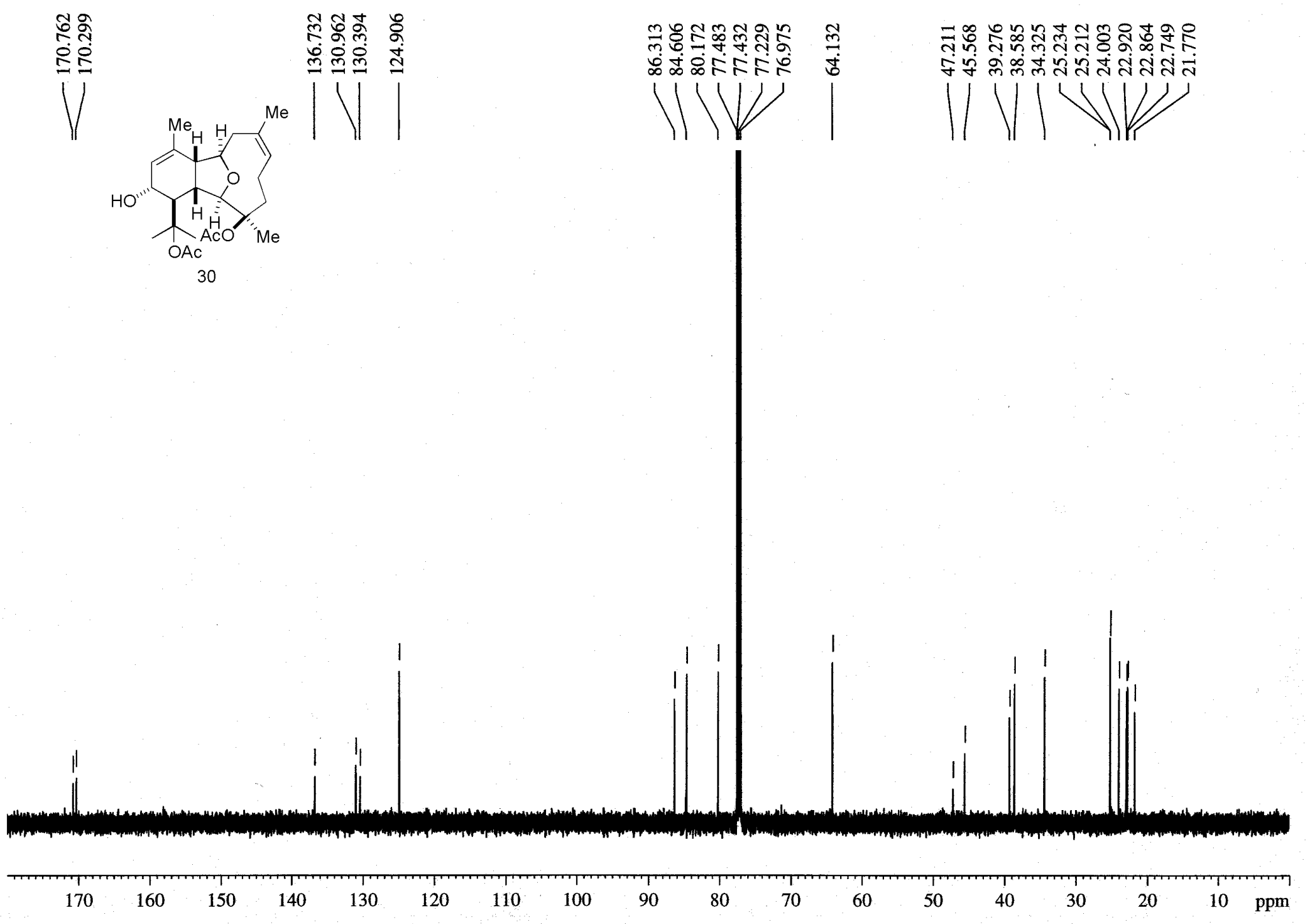


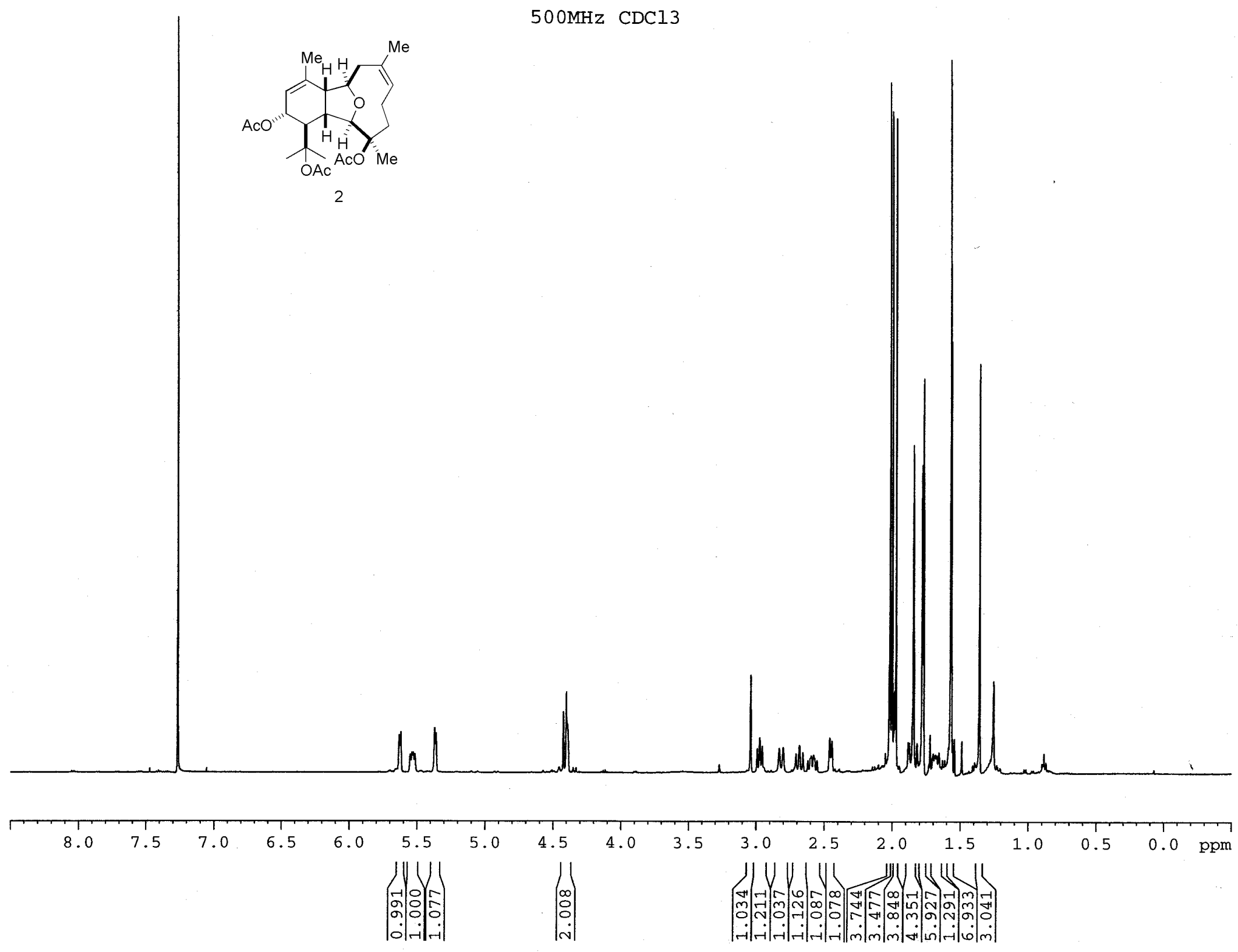


$500 \mathrm{MHz}$ CDC13
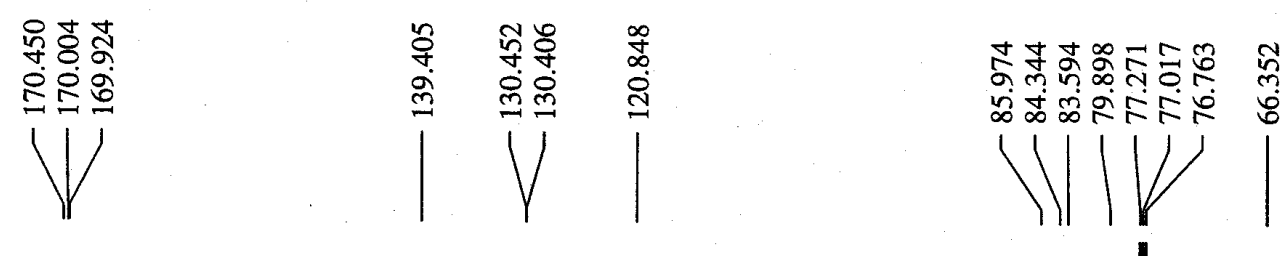

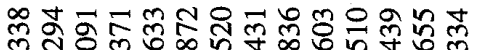

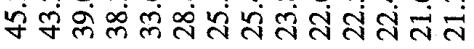
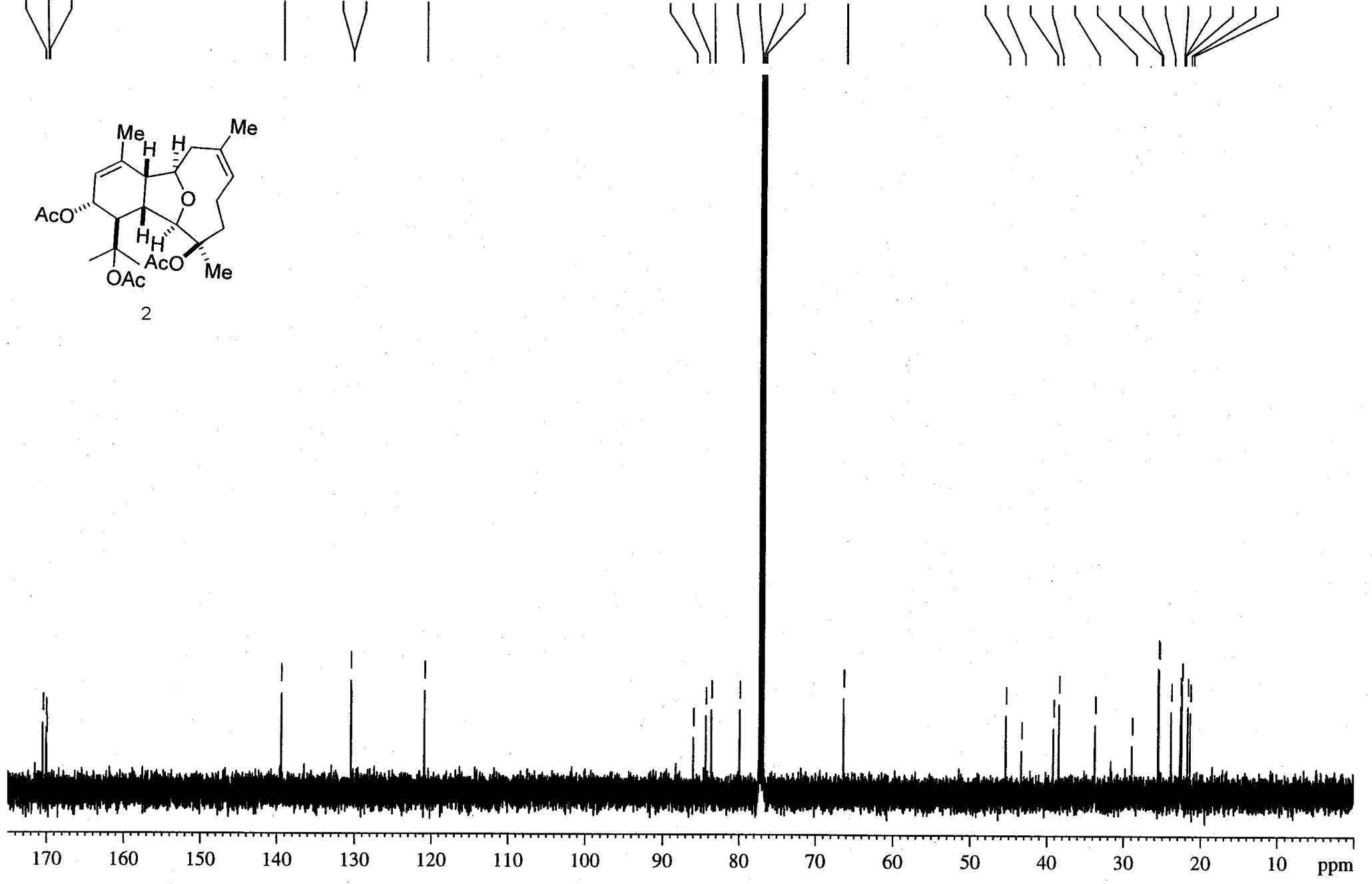
$400 \mathrm{MHz} \quad \mathrm{CDCl} 3$
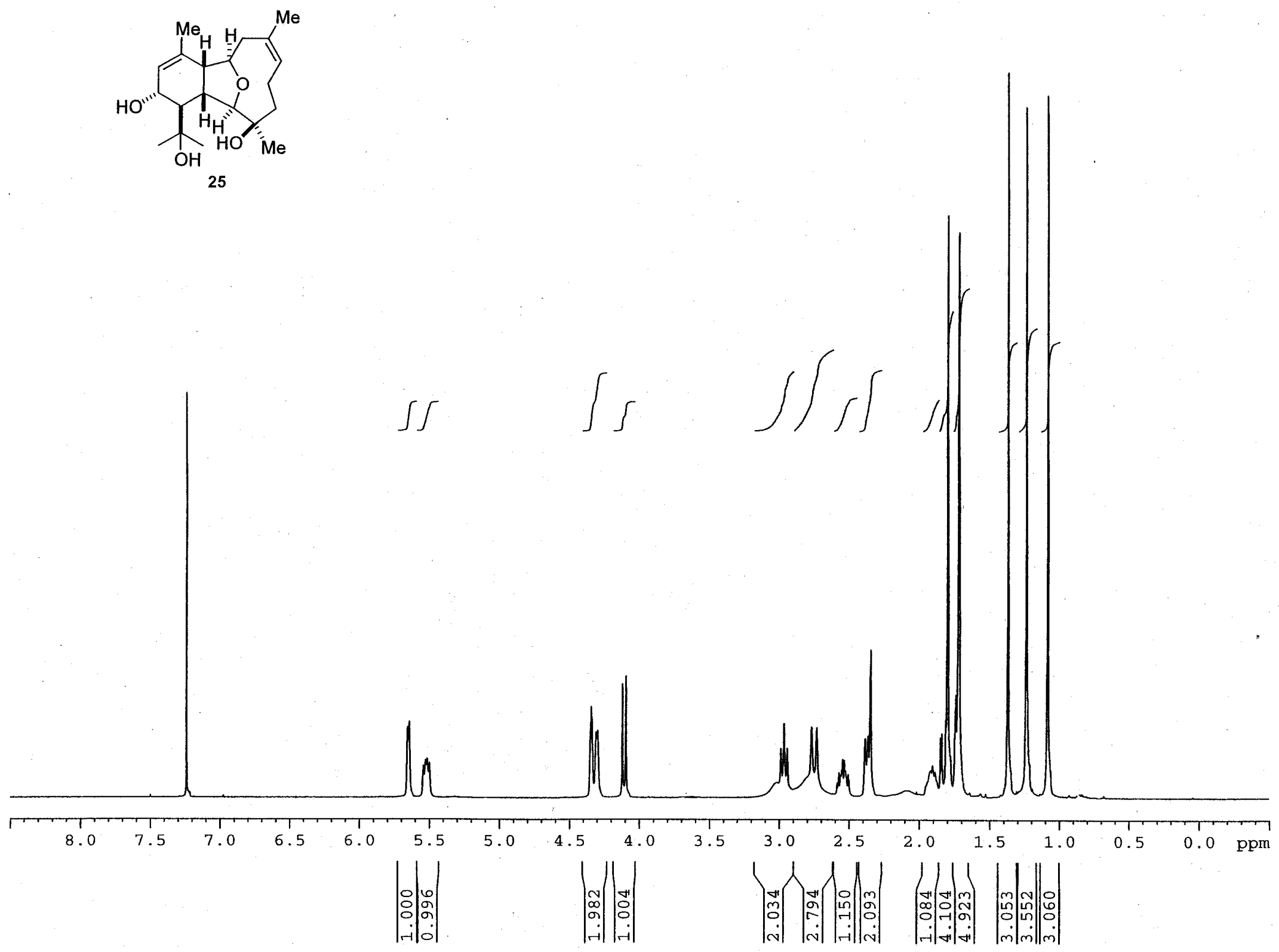


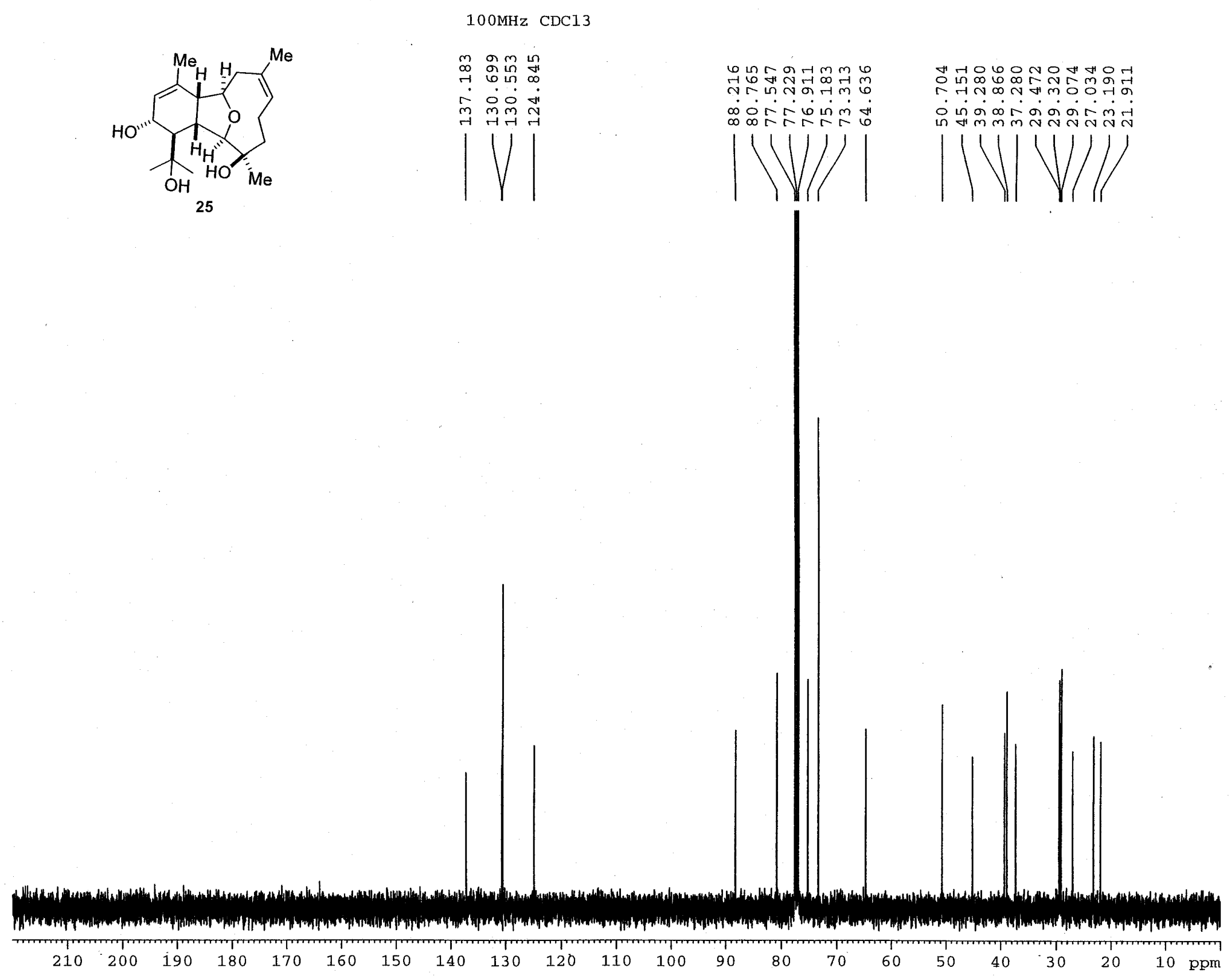




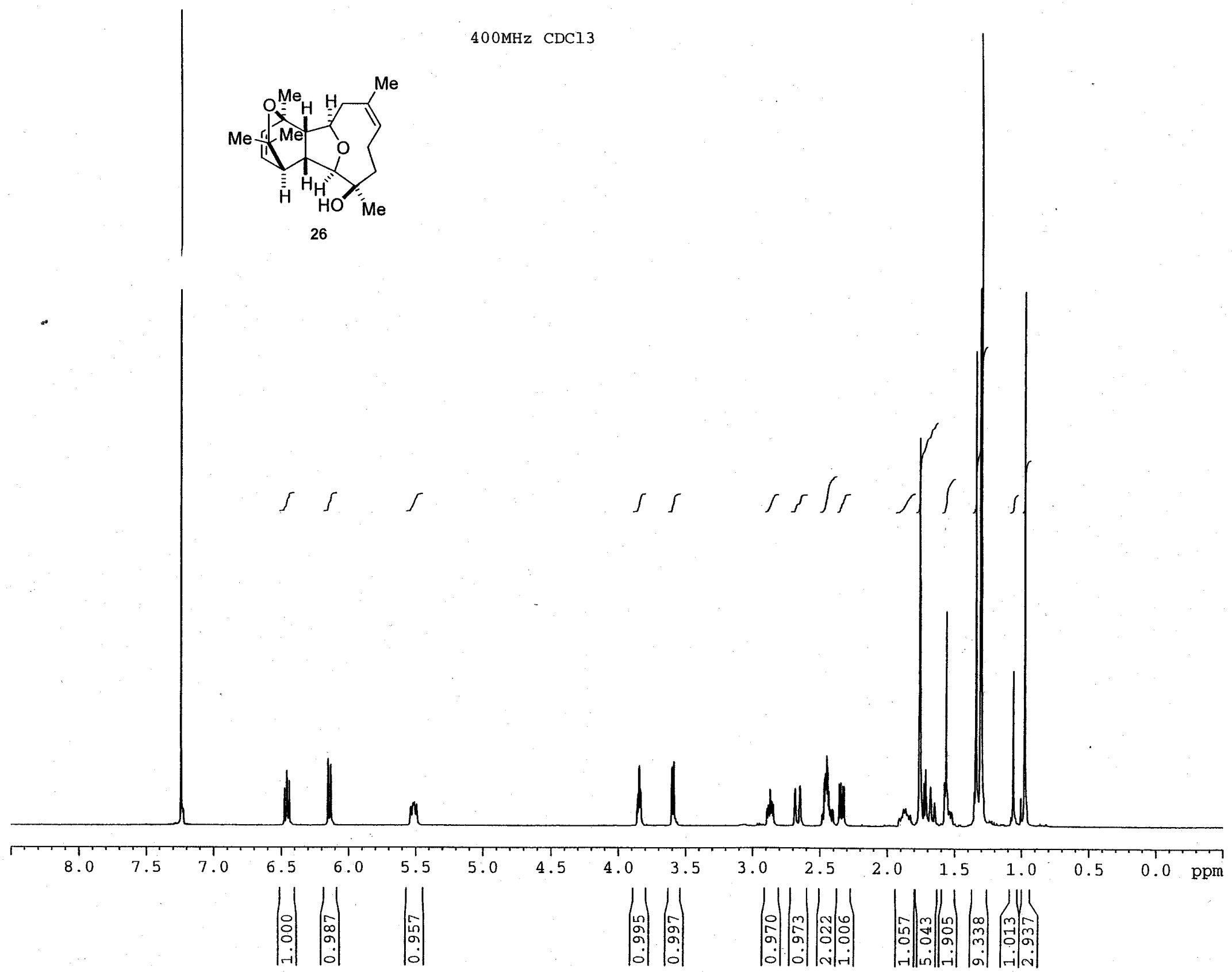

S54 
$100 \mathrm{MHz}$ CDCl 3
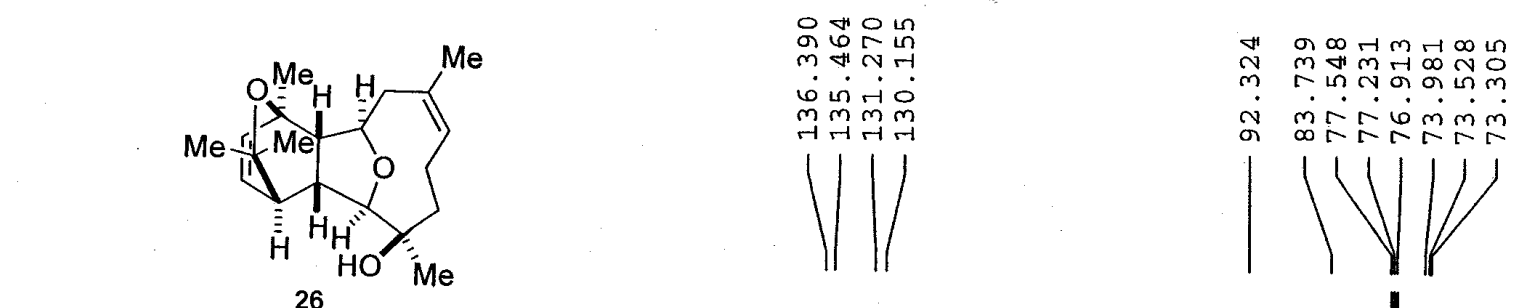

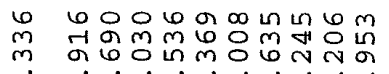

m

IVIVI

26

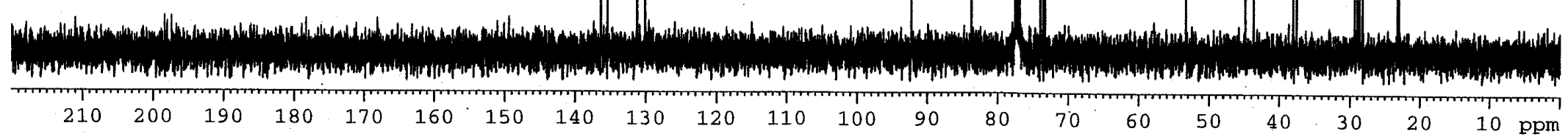

